\title{
What is considered cardiotoxicity of anthracyclines in animal studies
}

\author{
NIKOLAOS GEORGIADIS ${ }^{1,2^{*}}$, KONSTANTINOS TSAROUHAS $^{3 *}$, RAMIN REZAEE $^{4}$, HARITINI NEPKA $^{5}$, \\ GEORGE E.N. KASS ${ }^{6}$, JEAN-LOU C.M. DORNE ${ }^{6}$, DIMITRIOS STAGOS ${ }^{2}$, KONSTANTINOS TOUTOUZAS ${ }^{7}$, \\ DEMETRIOS A. SPANDIDOS ${ }^{8}$, DIMITRIOS KOURETAS $^{2}$ and CHRISTINA TSITSIMPIKOU ${ }^{2,9}$
}

\author{
${ }^{1}$ European Chemicals Agency, 00150 Helsinki, Finland; ${ }^{2}$ Department of Biochemistry and Biotechnology, \\ University of Thessaly, 41500 Larissa; ${ }^{3}$ Department of Cardiology, University Hospital of Larissa, 41334 Larissa, Greece; \\ ${ }^{4}$ Clinical Research Unit, Faculty of Medicine, Mashhad University of Medical Sciences, 9177948564 Mashhad, Iran; \\ ${ }^{5}$ Department of Pathology, University Hospital of Larissa, 41334 Larissa, Greece; ${ }^{6}$ European Food Safety Authority, \\ I-43126 Parma, Italy; ${ }^{7}$ First Department of Cardiology, Hippokration Hospital, Medical School, \\ University of Athens, 11527 Athens; ${ }^{8}$ Laboratory of Virology, Medical School, \\ University of Crete, 71003 Heraklion; ${ }^{9}$ Directorate of Energy, Industrial and Chemical Products, \\ General Chemical State Laboratory of Greece, 11521 Athens, Greece
}

Received June 12, 2020; Accepted July 14, 2020

DOI: $10.3892 /$ or.2020.7688

\begin{abstract}
Anthracyclines are commonly used anticancer drugs with well-known and extensively studied cardiotoxic effects in humans. In the clinical setting guidelines for assessing cardiotoxicity are well-established with important therapeutic implications. Cardiotoxicity in terms of impairment of
\end{abstract}

Correspondence to: Dr Christina Tsitsimpikou, Directorate of Energy, Industrial and Chemical Products, General Chemical State Laboratory of Greece, 16 Anastasiou Tsocha street, Ampelokipi, 11521 Athens, Greece

E-mail: chtsitsi@yahoo.com

Professor Dimitrios Kouretas, Department of Biochemistry and Biotechnology, University of Thessaly, Viopolis, 41500 Larissa, Greece

E-mail:dkouret@uth.gr

*Contributed equally

Abbreviations: LV, left ventricular; LVEF, LV ejection fraction; LVFS, LV fractional shortening; BNP, brain natriuretic peptide; PWT, posterior wall thickness; AWT, anterior wall thickness; SWT, septal wall thickness; BP, blood pressure; HR, heart rate; LVSP, LV systolic pressure; LVDP, LV diastolic pressure; LVEDd, LV end-diastolic diameter; LVESd, LV end-systolic diameter; LVEDV: LV end-diastolic volume; LVIDd, LV internal diastolic diameter; LVISd, LV internal systolic diameter; LVPWs, LV systolic wall thickness; LVPWd, LV diastolic wall thickness; IVSd, intraventricular septum in diastole; LAD, left atrial diameter; AOD, aortic diameter; ACEIs, angiotensin converting enzyme inhibitors; ARBs, angiotensin II receptor blockers

Key words: anthracyclines, echocardiography, ejection fraction, fractional shortening, rats cardiac function is largely diagnosed by echocardiography and based on objective metrics of cardiac function. Until this day, cardiotoxicity is not an endpoint in the current general toxicology and safety pharmacology preclinical studies, although other classes of drugs apart from anthracyclines, along with everyday chemicals have been shown to manifest cardiotoxic properties. Also, in the relevant literature there are not well-established objective criteria or reference values in order to uniformly characterize cardiotoxic adverse effects in animal models. This in depth review focuses on the evaluation of two important echocardiographic indices, namely ejection fraction and fractional shortening, in the literature concerning anthracycline administration to rats as the reference laboratory animal model. The analysis of the gathered data gives promising results and solid prospects for both, defining anthracycline cardiotoxicity objective values and delineating the guidelines for assessing cardiotoxicity as a separate hazard class in animal preclinical studies for regulatory purposes.

\section{Introduction}

Chemotherapeutics cardiotoxicity is a major concern for clinicians treating different kinds of cancer, as it seriously affects their treatment options and the survival of the patient. The cut-off values for the identification of cardiotoxicity caused by chemotherapeutics in humans differ between the American and European guidelines: the definition considers a lower cut-off value of normality for the left ventricular ejection fraction (LVEF) of 50\% in Europe (1) and 53\% in the USA (2). Both Guidelines emphasize that a drop of LVEF compared to the patient's previous values is also required. This definition is crucial for patients and clinicians, as patients presenting this decline in cardio-imaging indices of cardiac function should be treated with angiotensin converting enzyme inhibitors (ACEIs) or angiotensin II receptor blockers (ARBs) in 
combination with $\beta$-blockers (3); nevertheless, modifications of anticancer treatment in such patients remain a matter of discussion among different specialists.

In animal studies, where new anticancer substances are evaluated and different agents are tested to overcome anticancer drugs cardiotoxicity, identification of the extent of cardiotoxicity is crucial and necessary for the evaluation of any favourable effects of the counteracting agent (4). In this regard, cardiac imaging is more often used at analogy to the clinical setting. Biomarkers and clinical signs of heart failure are also taken into consideration, but cardiac imaging in animal studies has gained momentum.

Anthracyclines are a class of drugs used in cancer chemotherapy isolated from Streptomyces bacterium. These compounds are used to treat many cancers, including leukemias, lymphomas, as well as breast, stomach, uterine, ovarian, bladder cancer, and lung cancers (5-7). The first anthracycline discovered was daunorubicin (trade name Daunomycin), which is produced naturally by Streptomyces peucetius, a species of actinobacteria. Clinically, the most important anthracyclines are doxorubicin, daunorubicin, epirubicin and idarubicin. Anthracyclines, which are considered as well-established cardiotoxic compounds causing myocardial suppression in a considerable number of patients, are also used in animal studies as an easy and low-cost method to introduce a model of dilated cardiomyopathy (8), as opposed to interventional research animal models of infarction and myocardial ischaemia [e.g., permanent ligation of the left anterior descending artery (LAD) or cryo-pen application on the surface of the heart leading to cryo-scar ischemia]. Different animal species and various anthracyclines dosing and administration schemes have been applied in the literature for the development of anthracyclines cardiotoxicity (9) and monitoring of the progress thereof, as well as testing different compounds/schemes for ameliorating myocardial damage. To monitor cardiotoxicity caused by anthracyclines, cardiac imaging is primarily used and secondarily, biochemical markers.

At the same time, other pharmaceutical compounds, such as anabolic steroids, along with everyday chemicals, such as metals and pesticides, have been implicated to adversely affect cardiac pathology causing function impairment (10). Toxicity and risk for human health posed by chemicals are well controlled at a European level through a thoroughly developed regulatory network. Nevertheless, cardiotoxicity is not described as a separate hazard class and no specific classification criteria are available in order to legally classify chemicals well in advance as cardiotoxic and avoid potential long-term cardiovascular complications, which could significantly burden any national health system.

But, what is considered cardiotoxicity of anticancer agents and specifically anthracyclines when parameters of cardiac imaging are monitored in animal studies? Is there a uniformity in animal models of anthracyclines cardiotoxicity induction and most importantly, do all studies describe the same decline of myocardial function? Addressing these issues could be of wider use both in clinical medicine and practice, when assessing agents employed for salvation to cardiotoxic complications during oncology treatment, for example, as well as to regulators, when trying to establish reference values in echo- cardiographic function representing cardiotoxicity induced in animals by chemicals.

In the current in depth review, the identification of most commonly used metrics of myocardial function in animal studies of anthracycline induced cardiotoxicity are presented, along with the range of these values differentiating normal cardiac function from animals with pathological echocardiographic findings indicative of anthracycline cardiotoxicity as per author presentation.

\section{Materials and methods}

PubMed electronic database was systematically searched to detect all original research studies published until March 1, 2020, according to the Preferred Reporting Items for Systematic Reviews and Meta-analyses (PRISMA) statement (11). The specific literature search strategy used was: [AND ("*rats*” OR “*doxorubicin* OR “*echocardiography*" OR "anthracycline" OR “*ejection fraction*”)] either in the Title, or the Abstracts. The reference list of the retrieved studies was further evaluated for the relevance of the subject and the eligibility by screening the titles/abstracts of full papers. The non-English citations $(<5)$ were reviewed separately. Animal data only from rat species were assessed, as it is evident from the search string. All types of citations other than original research studies (e.g., review articles) were excluded. Two authors (NG and CT) independently assessed the title and the abstract content (or both) of each record retrieved to decide which studies should be further evaluated and extracted all data. Disagreements were resolved through consensus or by consultation with a third author (KT). A final draft of the manuscript was prepared after several revisions and approved by all authors. In total, 86 published manuscripts on animal studies were considered for the systematic review (Fig. 1).

Despite the small size of the rat heart and the fast heart rate, echocardiography is systematically used in the evaluation of rat heart function (12). Data for 2 main indices of LV contractility were extracted from the list of studies.

The first index is LV fractional shortening (FS) and is calculated by the formula: FS $(\%)=[\mathrm{LV}$ end-diastolic diameter $\left(\mathrm{LVD}_{\mathrm{d}}\right)$ minus LV end-systolic diameter $\left.\left(\mathrm{LVD}_{\mathrm{s}}\right)\right] / \mathrm{LVD}_{\mathrm{d}} \mathrm{x} 100$.

LVEF is the second and more common, index of LV contractility. EF can be calculated from the equation: $\mathrm{EF}(\%)$ $=\left[\left(\mathrm{LVD}_{\mathrm{d}}{ }^{3}-\mathrm{LVD}_{\mathrm{s}}{ }^{3}\right) / \mathrm{LVD}_{\mathrm{d}}{ }^{3}\right] \times 100(13)$ or from the equation: $\mathrm{EF}(\%)=($ LVEDV-LVESV $) /$ LVEDV $\times 100$, where LVEDV is the LV end-diastolic volume and LVESV is LV end-systolic volume (12).

\section{Results}

A summary of the studies reviewed in the present report is presented in Table I.

In Figs. 2-5, the normal and suppressed values of the two main echocardiographic indices discussed, \%EF and $\%$ FS, respectively, are presented. Reported baseline (normal) $\%$ EF values in rats vary $(55-96.5 \%)$. In $78.2 \%$ of the studies reviewed, normal values range from 70 to $90 \%$. High $\% \mathrm{EF}$ values $(>90 \%)$ are reported in $14 \%$ of the studies. In contrast, normal \%FS values present even higher variability (25-84.2\%). 


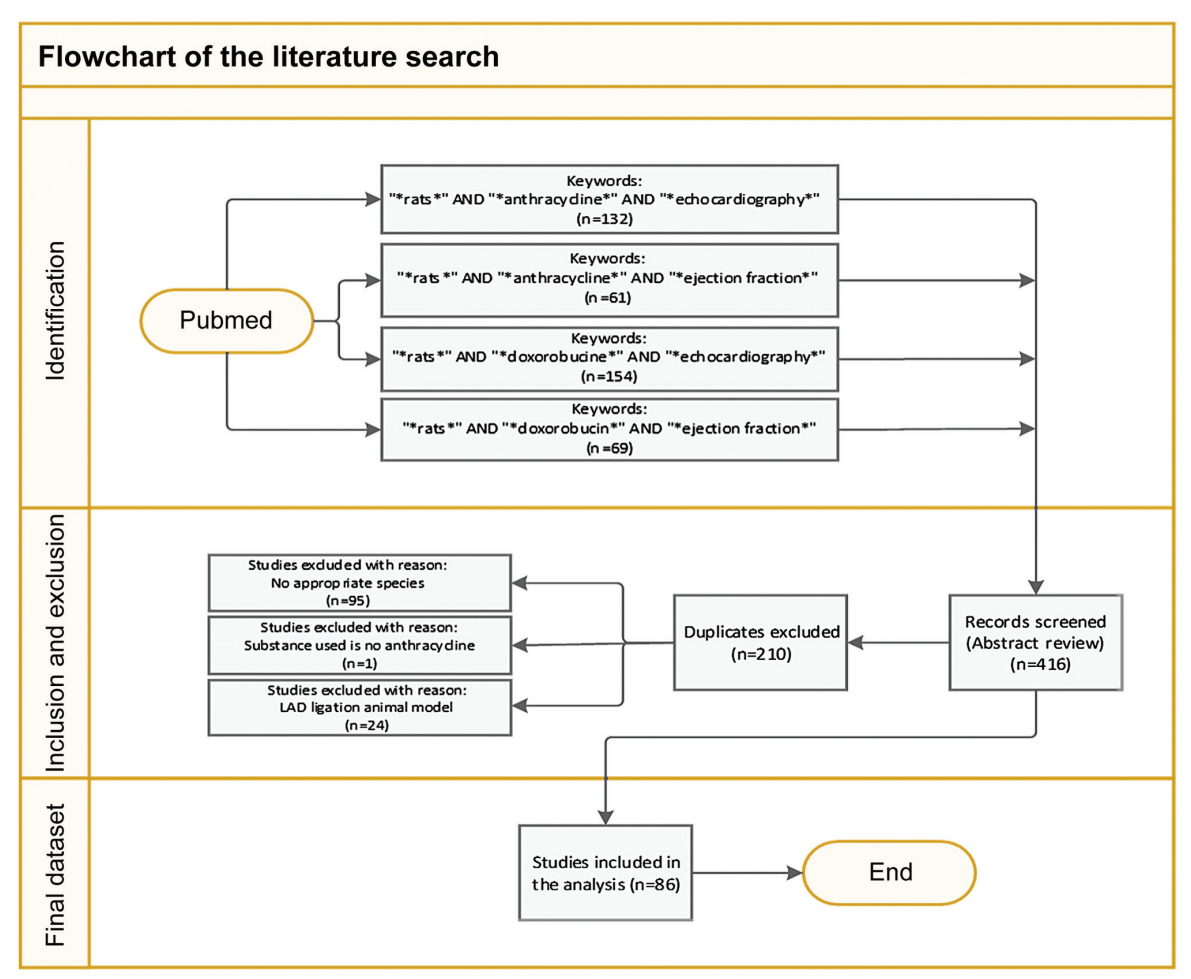

Figure 1. Prisma flow chart (literature search) for the present study design.

The majority $(66.7 \%)$ of the values, though, are reported to be within the range of 40 and $60 \%$.

Exposure to anthracyclines suppresses both echocardiographic indices. In the 86 studies reviewed in the present report, Doxorubicin is almost universally used to induce cardiotoxicity, along with Daunorubicin and Epirubicin in two studies (Table I). The structures of the three anthracyclines used are presented in Fig. 6. Anthracyclines were administered with order of appearance either via intraperitoneal injection, intravenous injection or orally with the feed. The doses were administered once, twice, three times per week. The duration of the dose administration spans from one week to ten weeks. In most of the experiments, the benchmark for terminating the administration was the proof of cardiac toxicity. The echocardiography values suggest that there is no specific dose regime threshold which indicates the establishment of the effect, but it is specific to each experiment and probably dependent on other factors such as age and general condition of the animals.

The suppressed \%EF values reported from rats after anthracyclines administration vary from 31 to $91 \%$ (Fig. 4). EF values $50-80 \%$ are reported in $72.3 \%$ of the studies reviewed. Suppression of the $\% \mathrm{EF}$ due to anthracycline administration varies from 10 to $40 \%$ compared to the normal values in more than two thirds of the studies reviewed (71.7\%) (Fig. 7). On the other hand, suppressed \%FS values ranging from 14 to $71.8 \%$, present a more narrow distribution (\%FS values $20-50 \%$ in $84.6 \%$ of the studies). As shown in Fig. 7, a more equal distribution of the $\%$ FS suppression due to anthracycline toxicity is observed with approximately one fourth of the studies reporting $20-30 \%$ and $30-40 \%$ suppression, respectively. It is evident from Figs 8 and 9 that normal and suppressed \%EF and $\%$ FS values separate sufficiently well. The rat strain does not seem to influence either the normal or the suppressed $\% \mathrm{EF}$ and \%FS values (Fig. 10).

Only 11 studies used an acute administration scheme, with 3-20 mg/kg bw anthracycline single injection either intravenously or intraperitoneally. Most of the studies used a prolonged administration period, from 2 weeks ( 33 studies) up to 10 weeks, and cumulative doses ranging from 1 to $20 \mathrm{mg} / \mathrm{kg}$ bw. All dosage schemes were carefully selected to induce cardiotoxicity and did not seem to affect the suppression of $\% \mathrm{EF}$ and $\% \mathrm{FS}$ monitored.

\section{Discussion}

Myocardial contractility suppression due to anthracycline administration is of increasing interest and represents a major challenge in the clinical setting. At the same time in a preclinical stage it serves as a model for the assessment of both new chemotherapeutic and cardioprotective agents to be introduced in clinical practice. The myocardial toxicity of anthracyclines is known to be affected by sex and age, along with a number of cardiovascular risk factors and comorbidities (99). It is found that anthracycline related congestive heart failure reaches $10 \%$ of patients older than 65 years at usual doses (100). While in early studies it was thought that EF cannot accurately predict congestive heart failure attributed to doxorubicin (100), current perspective is that anthracycline-related cardiotoxicity is manifested by a progressive continuous decline in LVEF (1) and identifying subclinical myocardial dysfunction related to anthracycline treatment has great therapeutic implications (2).

Preclinical animal studies areessential in cancerchemotherapy research along with the evaluation of the cardiotoxic propensity of the chemotherapeutic agents. The current recommendations for prevention of cardiac events from cancer chemotherapies are 


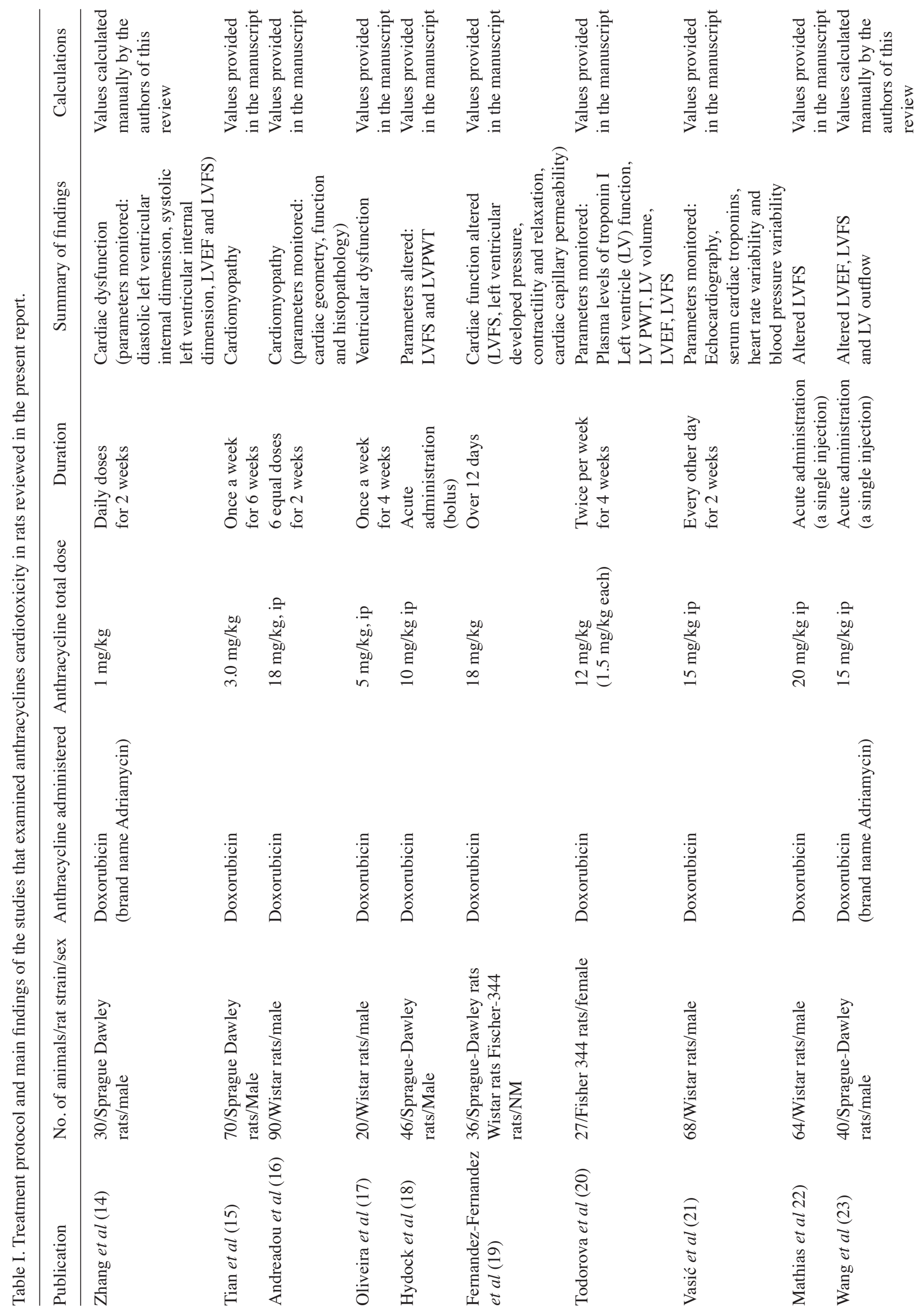




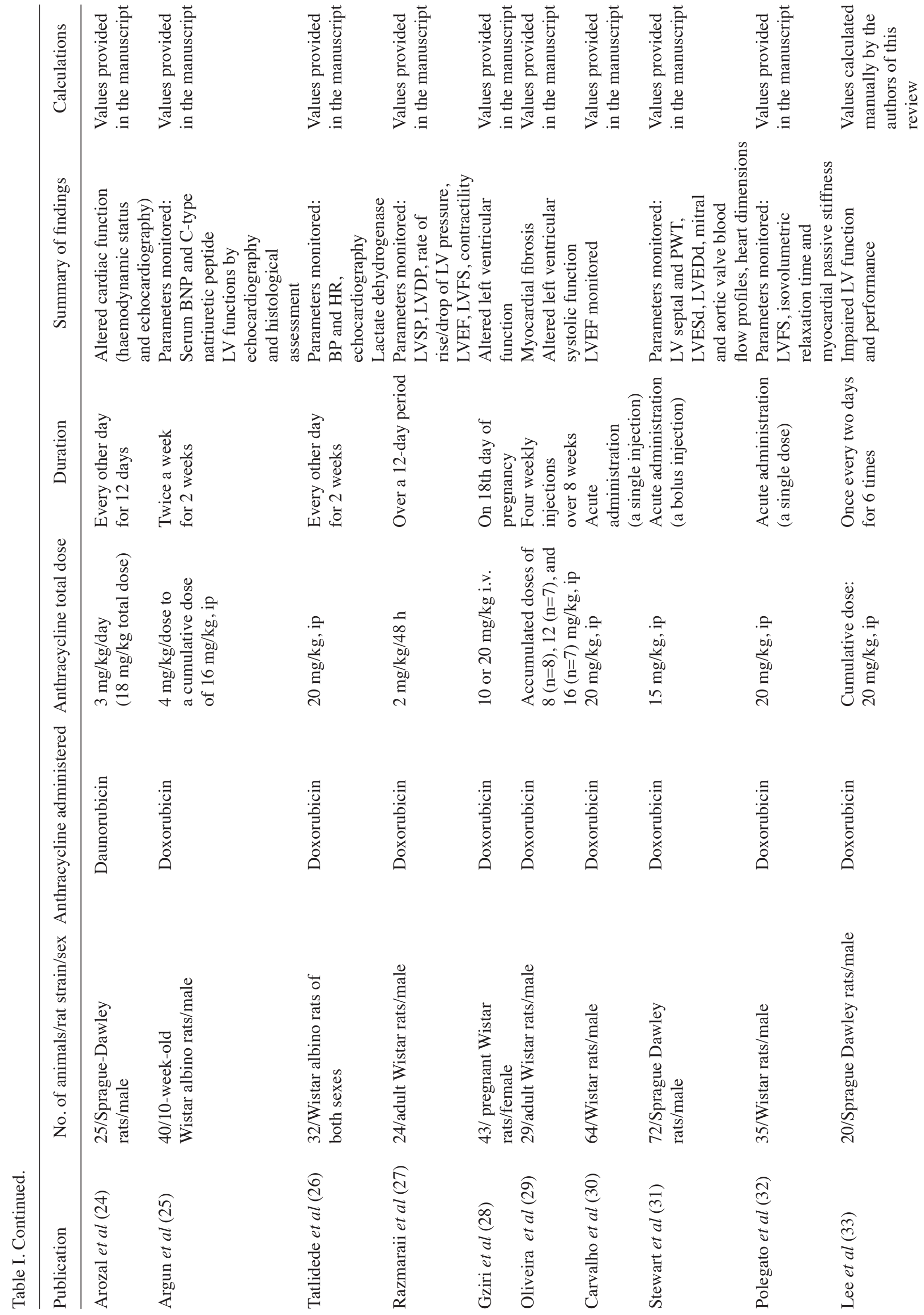




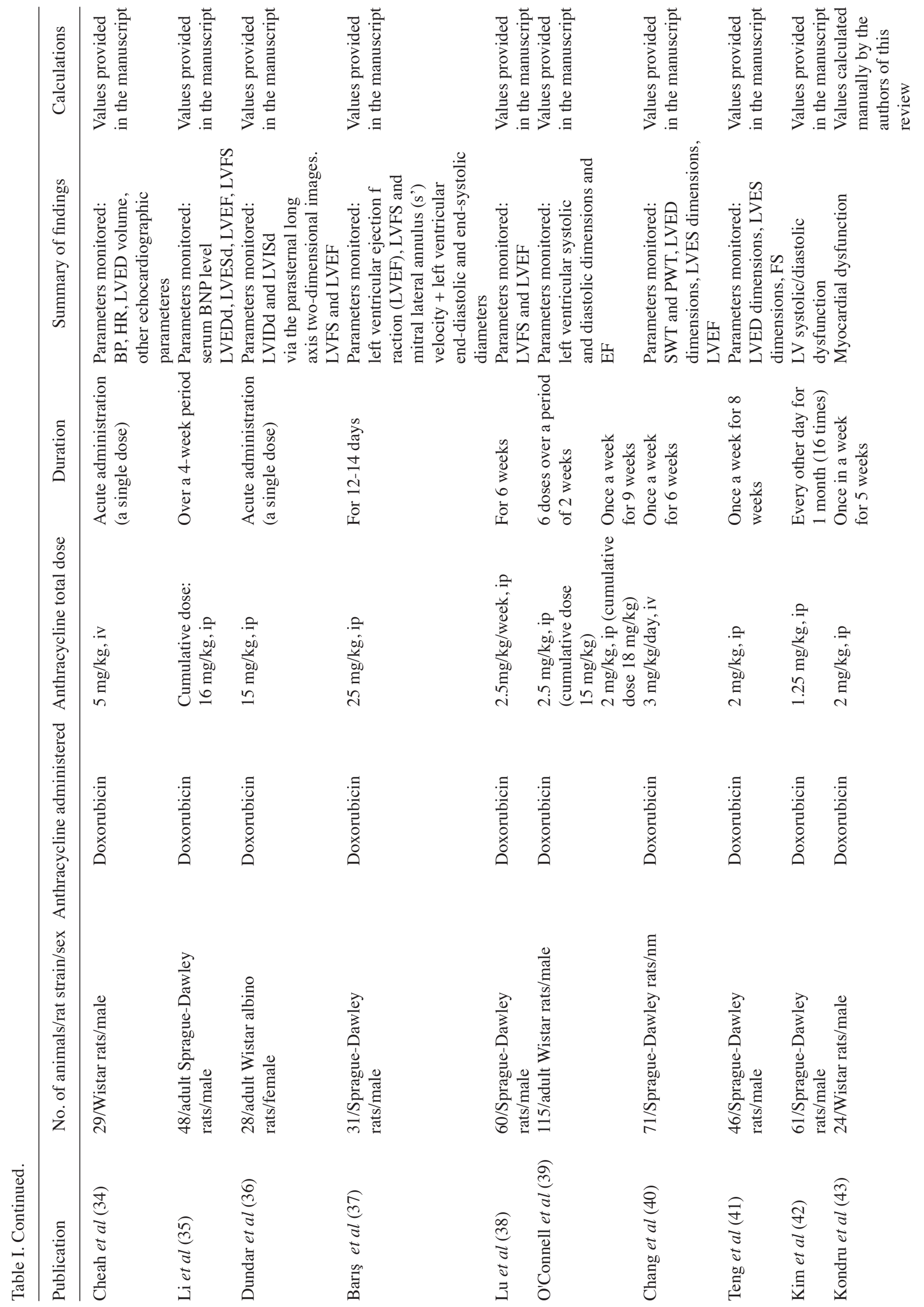




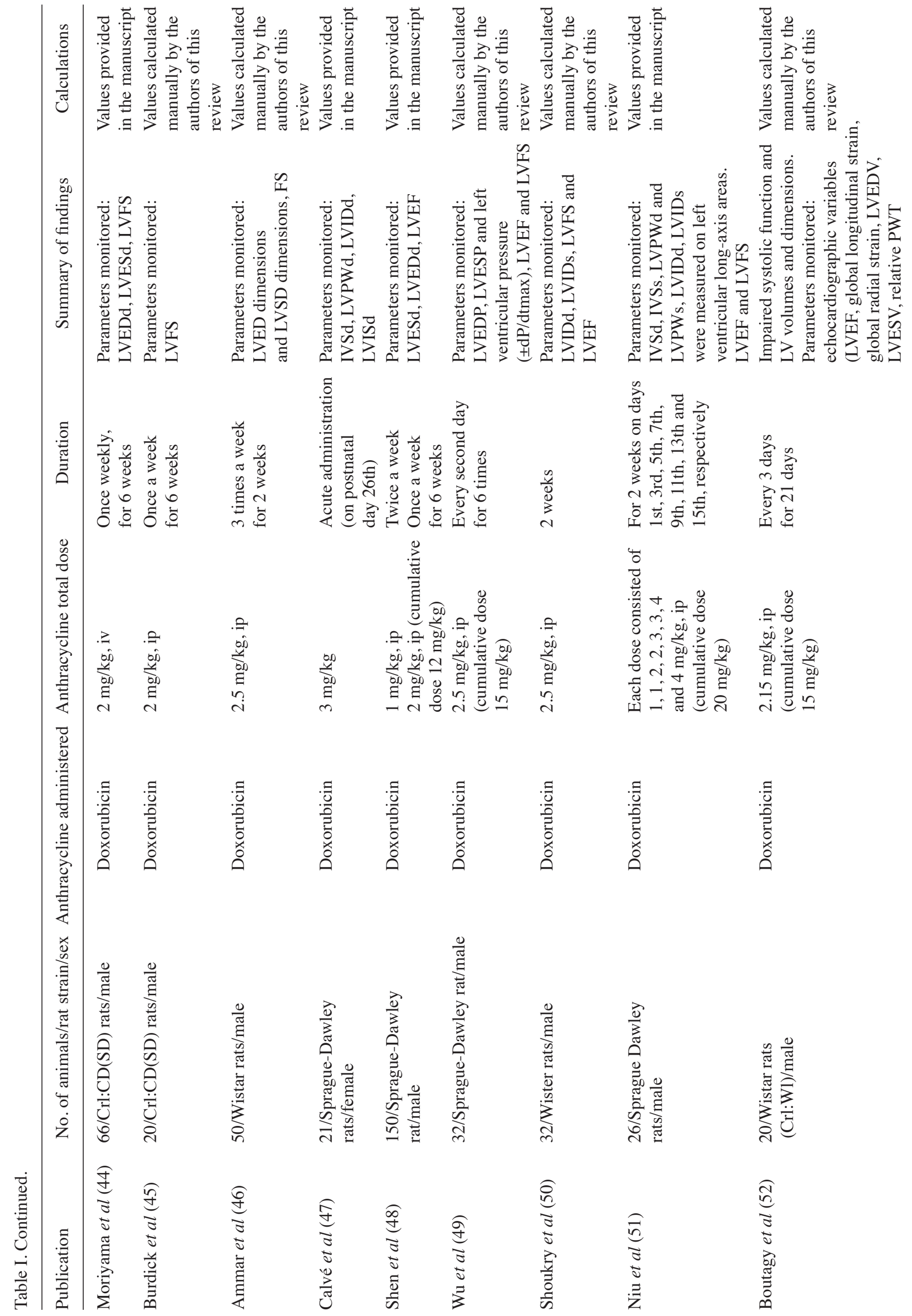




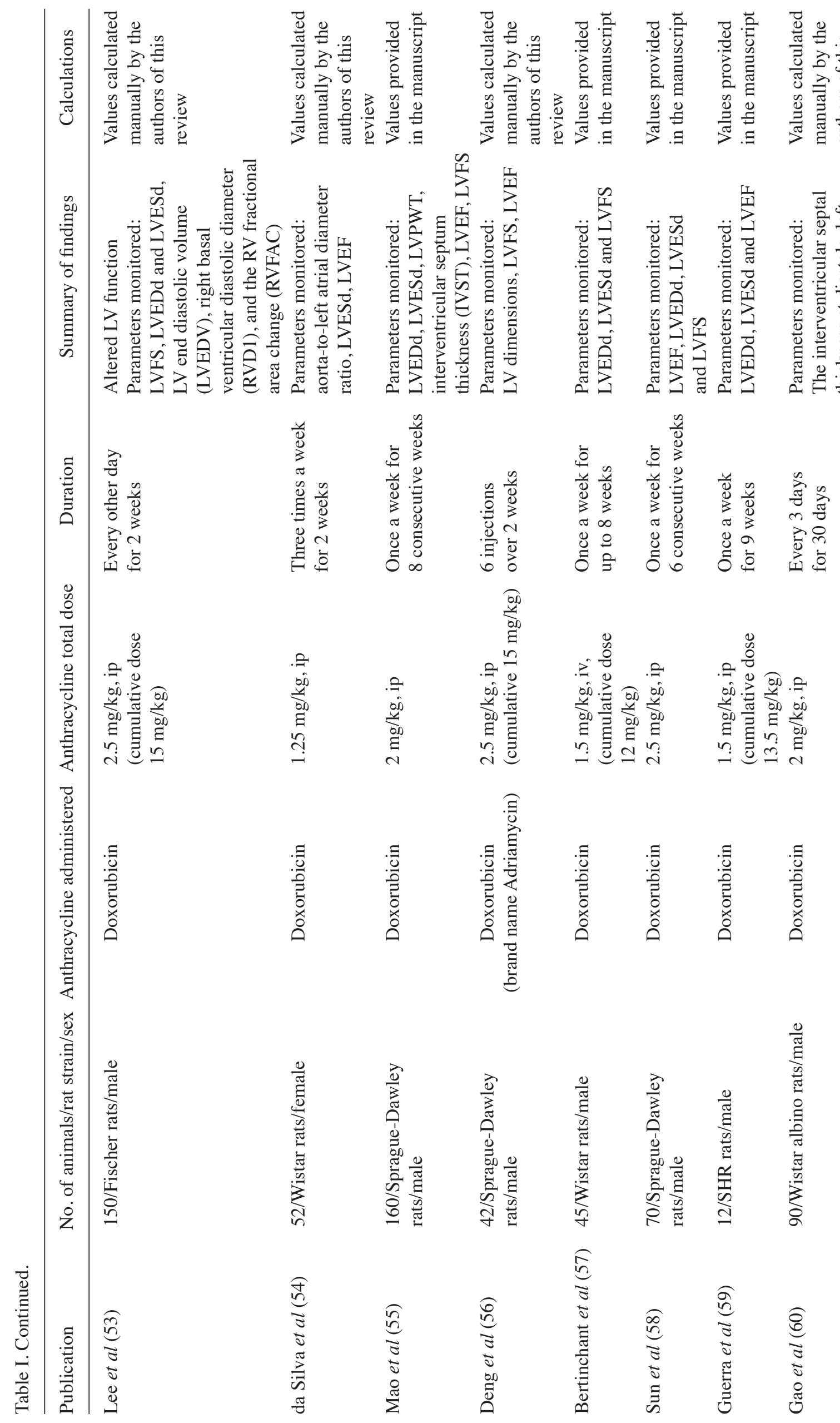




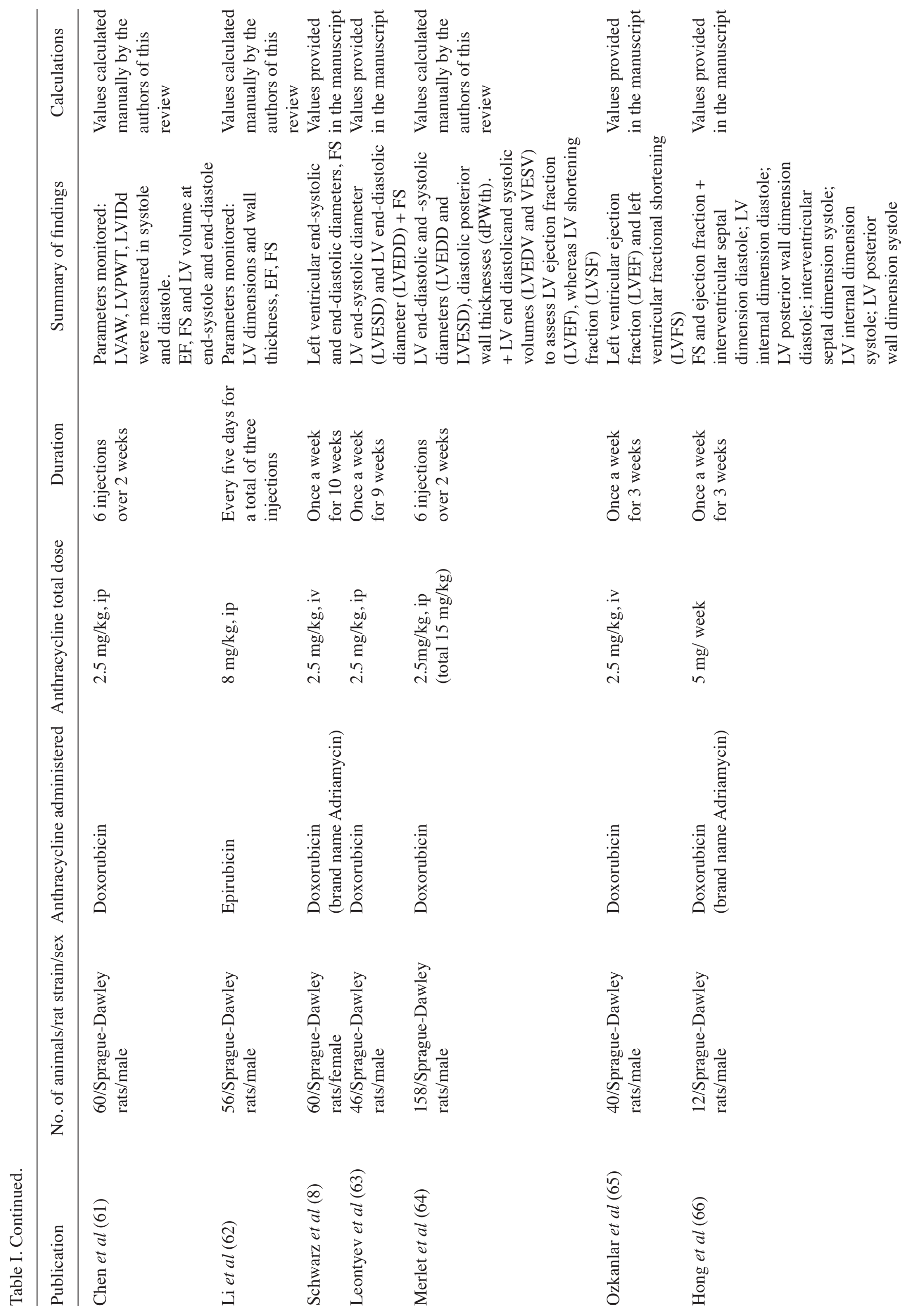




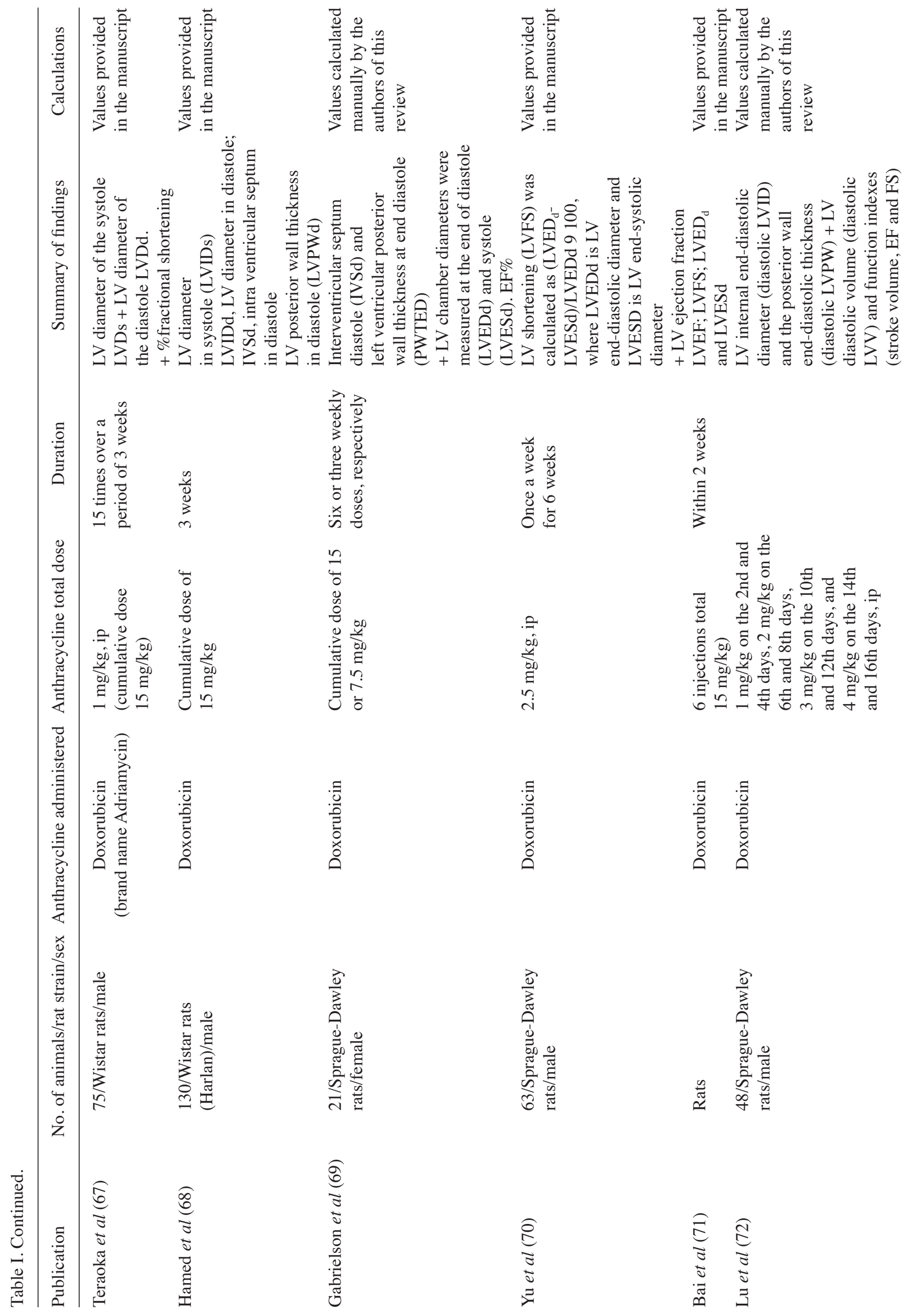




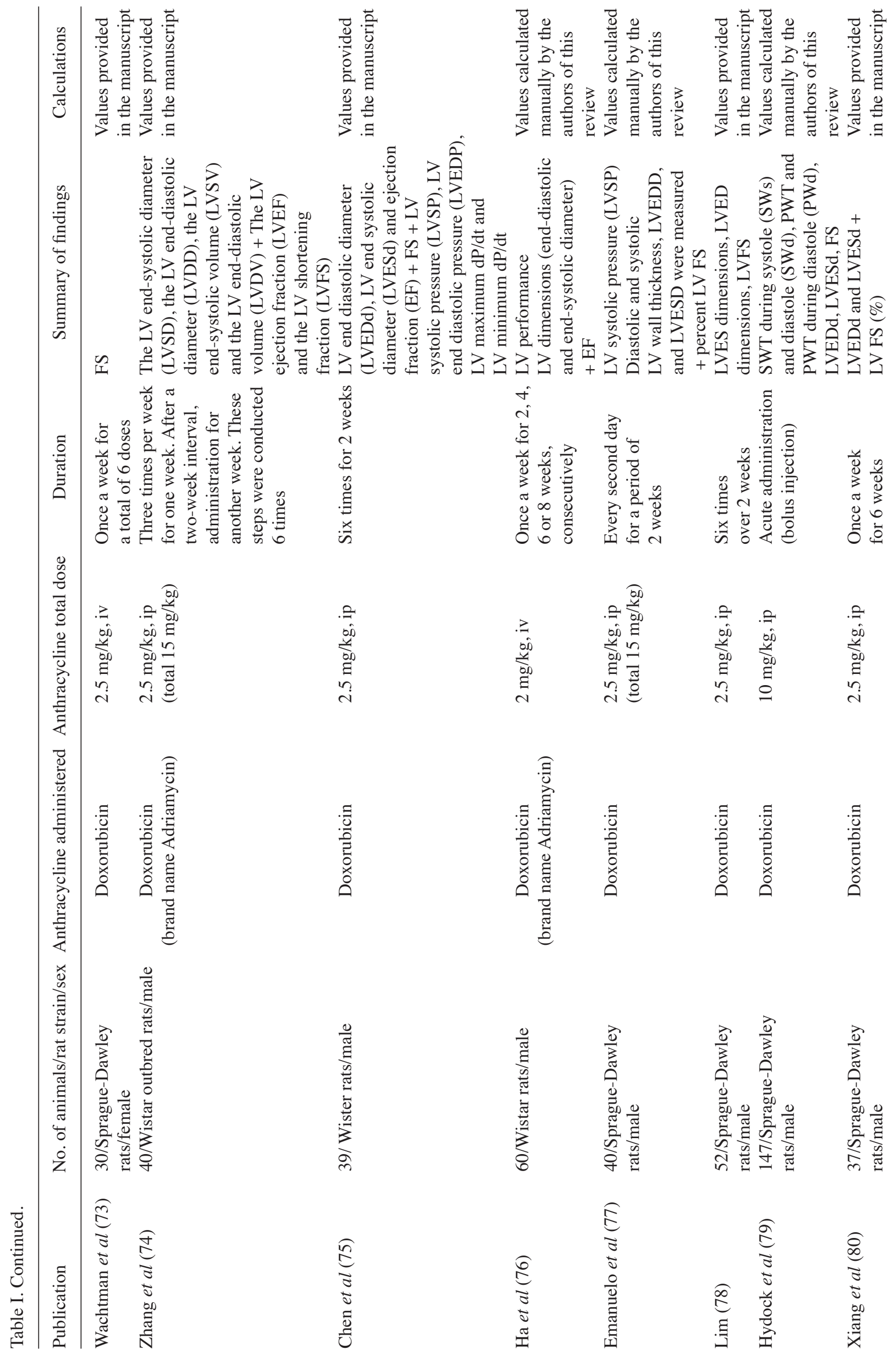




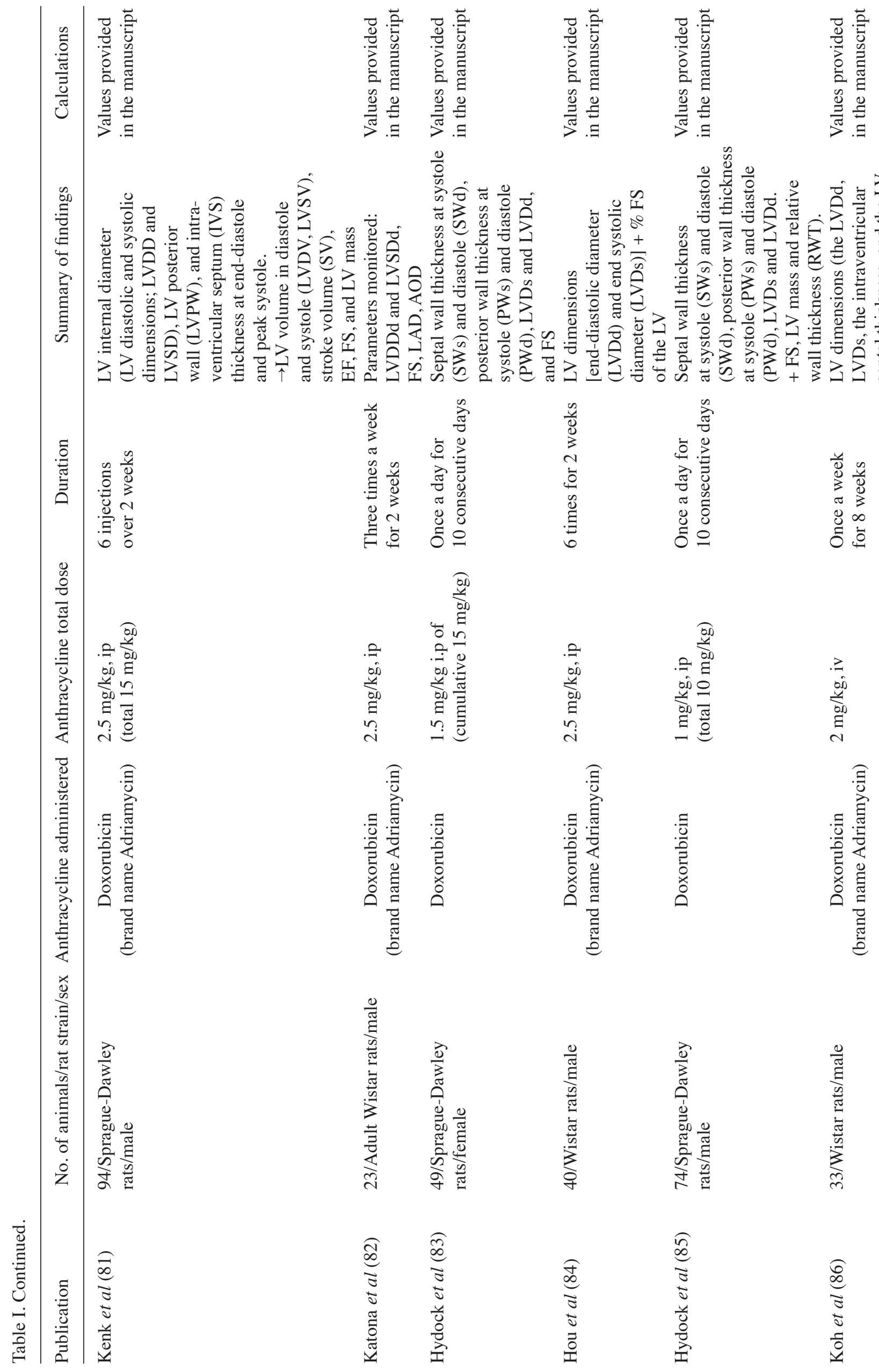




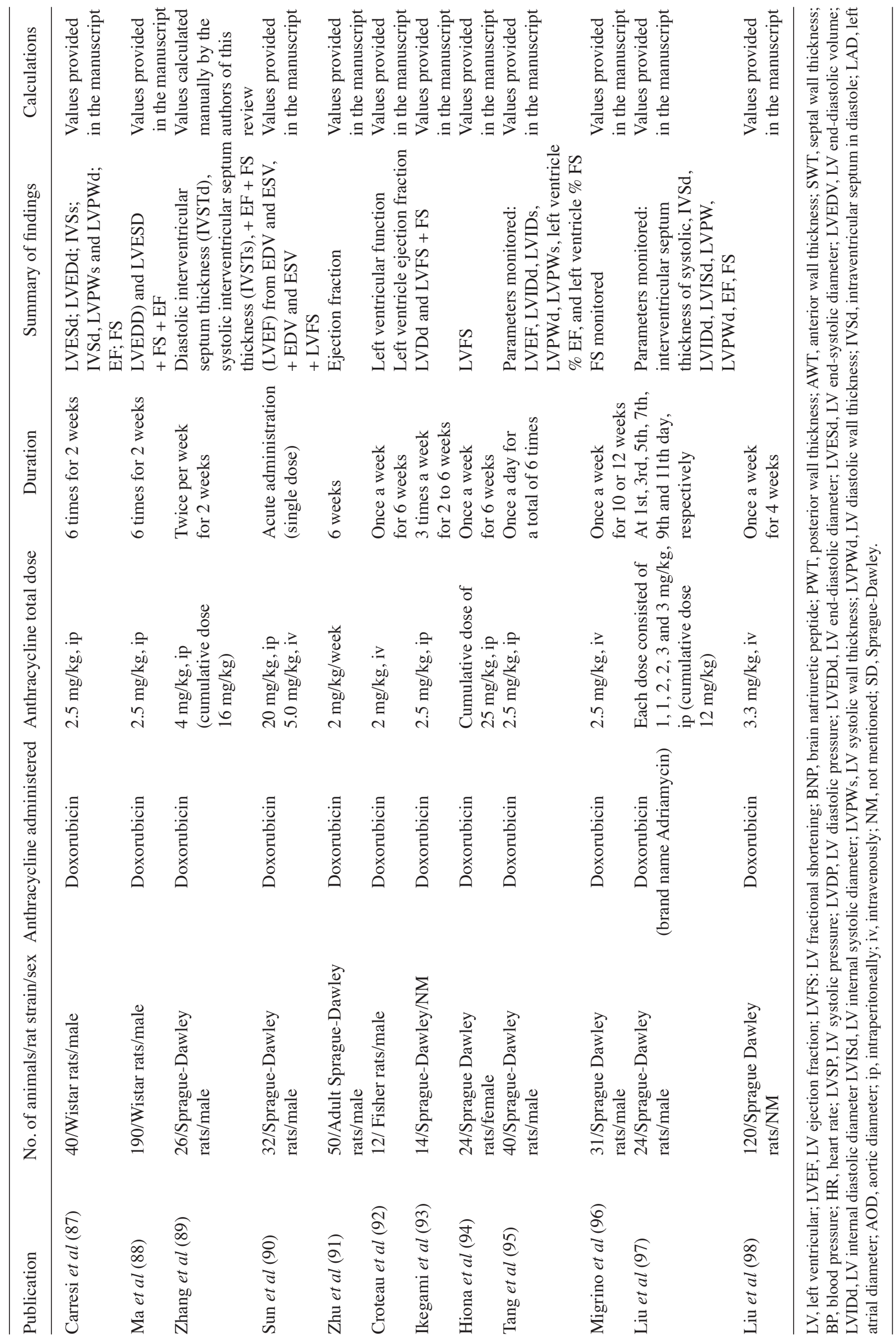


Normal LVEF values in rats

\begin{tabular}{|c|c|c|}
\hline$\rightarrow$ (Zhang H et al, 2018) & $\rightarrow$ (Ozkanlar et al, 2014) & $\rightarrow-($ Todorova et al, 2011) \\
\hline$\rightarrow$ - (Vasic et al, 2019) & $\multimap-($ Wang et al, 2015) & $\multimap$ (Bariset al, 2019) \\
\hline$\rightarrow($ Arozal et al, 2010) & $\rightarrow$ (Argun et al, 2016) & $\rightarrow$ (Tatlidede et al, 2009) \\
\hline$\rightarrow$ (Oliveira et al, 2013) & $\rightarrow$ (Carvalho et al, 2016) & $\leadsto-($ Razmaraii et al, 2016) \\
\hline$\rightarrow$ (Cheah et al, 2017) & $\rightarrow-($ Liet al, 2019) & $\rightarrow$ (Dundar et al, 2016) \\
\hline$\rightarrow$ (Lu et al 2016) & $\rightarrow\left(O^{\prime}\right.$ Connell et al, 2017) & $\rightarrow$ (Chang et al, 2015) \\
\hline$\rightarrow$ (Teng et al, 2010) & $\rightarrow$ (Kim et al, 2012) & $\rightarrow$ (Kondru et al, 2017) \\
\hline$\multimap-($ Shen et al, 2016) & $\multimap-($ Wu et al, 2019) & $\multimap-($ Shoukry et al, 2017) \\
\hline$\longrightarrow$ (Boutagy et al, 2018) & $\rightarrow$ (Lee et al, 2017) & $\rightarrow$ (da Silva et al, 2012) \\
\hline$\longrightarrow$ (Deng et al, 2017) & $\rightarrow($ Sun R, et al, 2017) & $\rightarrow$ (Guerra et al, 2005) \\
\hline$\multimap-($ Gao et al, 2016) & $\rightarrow-($ Chen et al, 2015) & $\rightarrow-$ (Liet al, 2016) \\
\hline$\multimap-($ Merlet et al, 2013) & $\rightarrow-($ Hong et al, 2017) & $\multimap-($ Gabrielson et al, 2008) \\
\hline$\rightarrow$ (Yu et al, 2014) & $\rightarrow-$ (Lu et al, 2015) & $\rightarrow$ (Zhang et al, 2012) \\
\hline$\rightarrow($ Chen et al, 2007) & $\rightarrow-($ Ha et al, 2005) & $\multimap($ Kenk et al, 2010) \\
\hline$\multimap-($ Carresi et al, 2018) & $\rightarrow-$ (Ma et al, 2017) & $\rightarrow-($ Sun XP, et al, 2017) \\
\hline$\multimap($ Croteau et al, 2014) & $\rightarrow$ (Tang et al, 2013) & $\rightarrow$ (Tian et al, 2017) \\
\hline$\rightarrow$ (Liu et al, 2006) & $\rightarrow-($ Read et al, 2018) & $\rightarrow-$ (Nichols et al, 2015) \\
\hline$\longrightarrow$ —(Oláh et al, 2018) & $\rightarrow$ (Polegato et al, 2015) & $\multimap-($ Niu et al, 2015) \\
\hline - (Mao et al, 2017) & $\rightarrow$ (Zhang XJet al, 2017) & $\rightarrow$ (Liu et al, 2018) \\
\hline
\end{tabular}

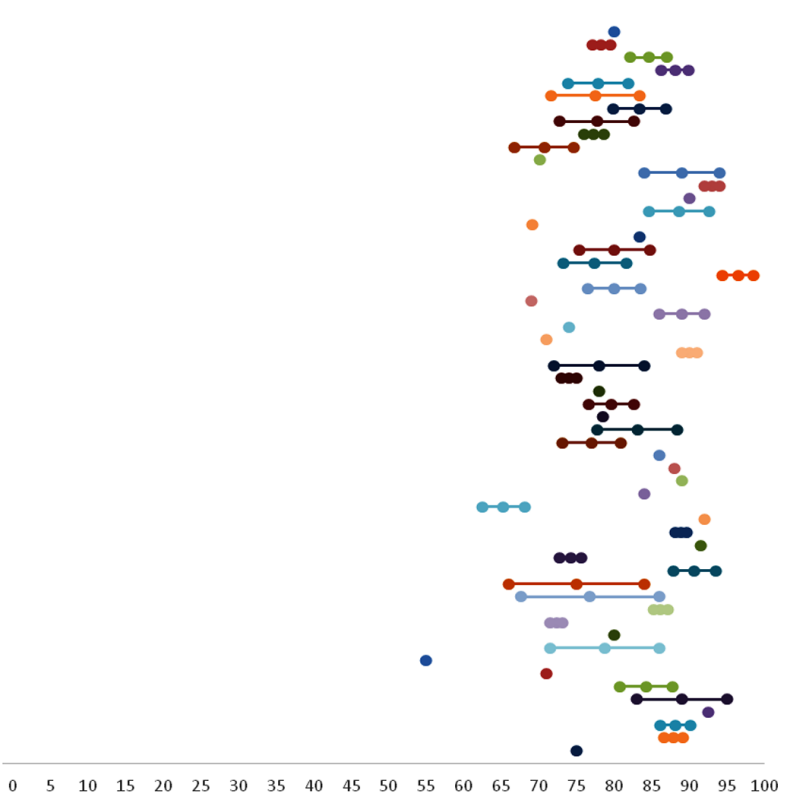

LVEF

Figure 2. Normal (baseline) LVEF values in rats before anthracycline administration as reported in 57 relevant studies reviewed in the present report. LVEF, left ventricular ejection fraction.

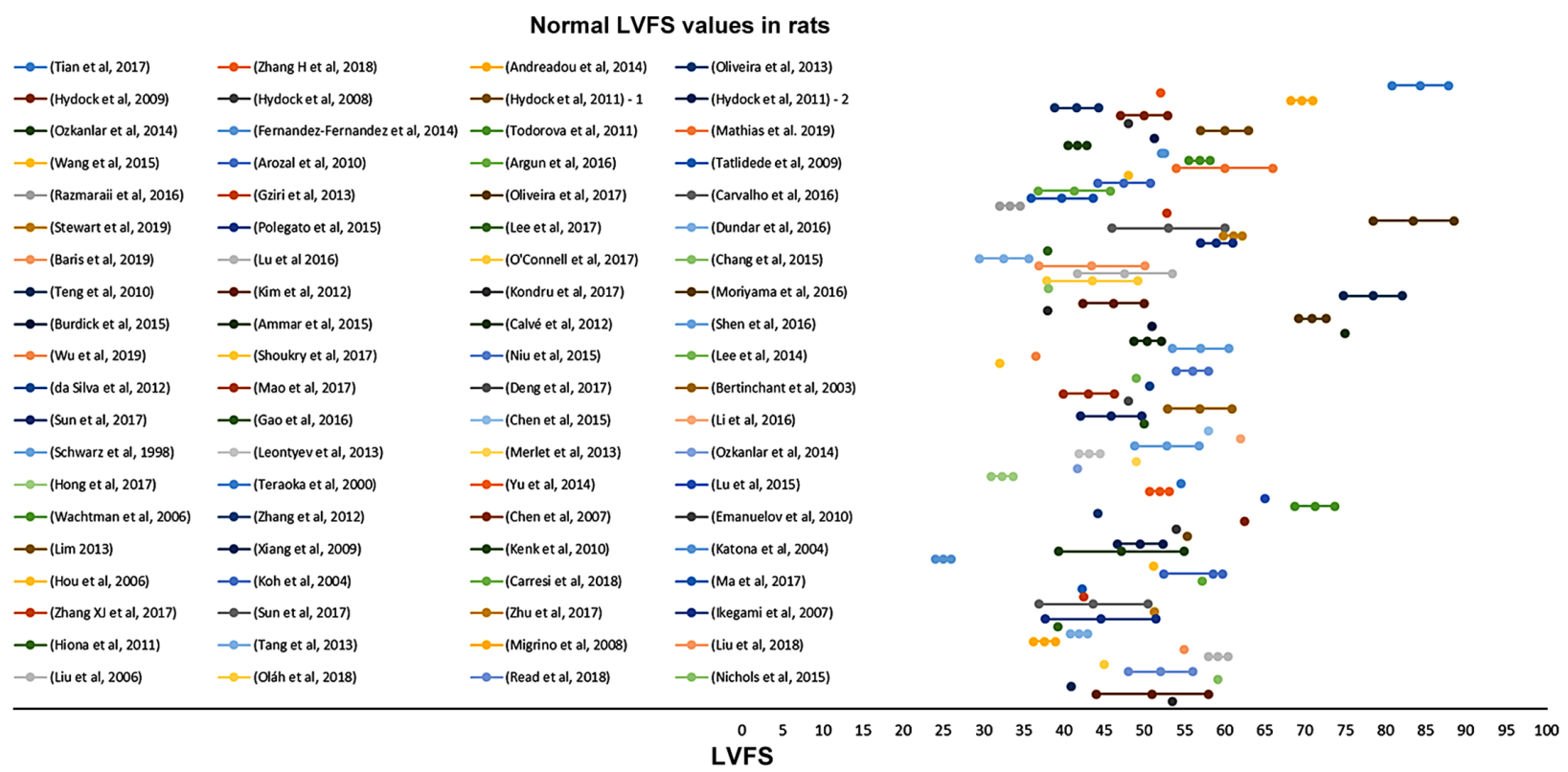

Figure 3. Normal (baseline) LVFS values in rats before anthracycline administration as reported in 80 relevant studies reviewed in the present report. LVFS, left ventricular fractional shortening.

largely based on recommendations. The American Society of Clinical Oncology, for example, recommends active screening and prevention of modifiable cardiovascular risk factors, such as tobacco use, high blood pressure, high cholesterol, alcohol use, obesity and physical inactivity (101). A well characterized animal model for defining cardiotoxicity due to chemotherapy and the treatment thereof is of great importance for clinical practice, as it will enable physicians to base their decisions not only on epidemiology but also on observations developed using concrete data from animal studies.
In the present review, the range of the main echocardiographic indices, namely EF and FS, used in describing anthracycline cardiotoxicity in rats was summarized along with the normal values of the said indices presented in the respective studies. In the graphic representation, it seems that normal and suppressed values due to anthracyclines administration for the two echocardiographic indices are well separated. This provides the first evidence for the possibility of setting a cut-off point for defining anthracycline cardiotoxicity in rats with an in-depth future meta-analysis. 
Suppressed LVEF in rats due to anthracyclines toxicity

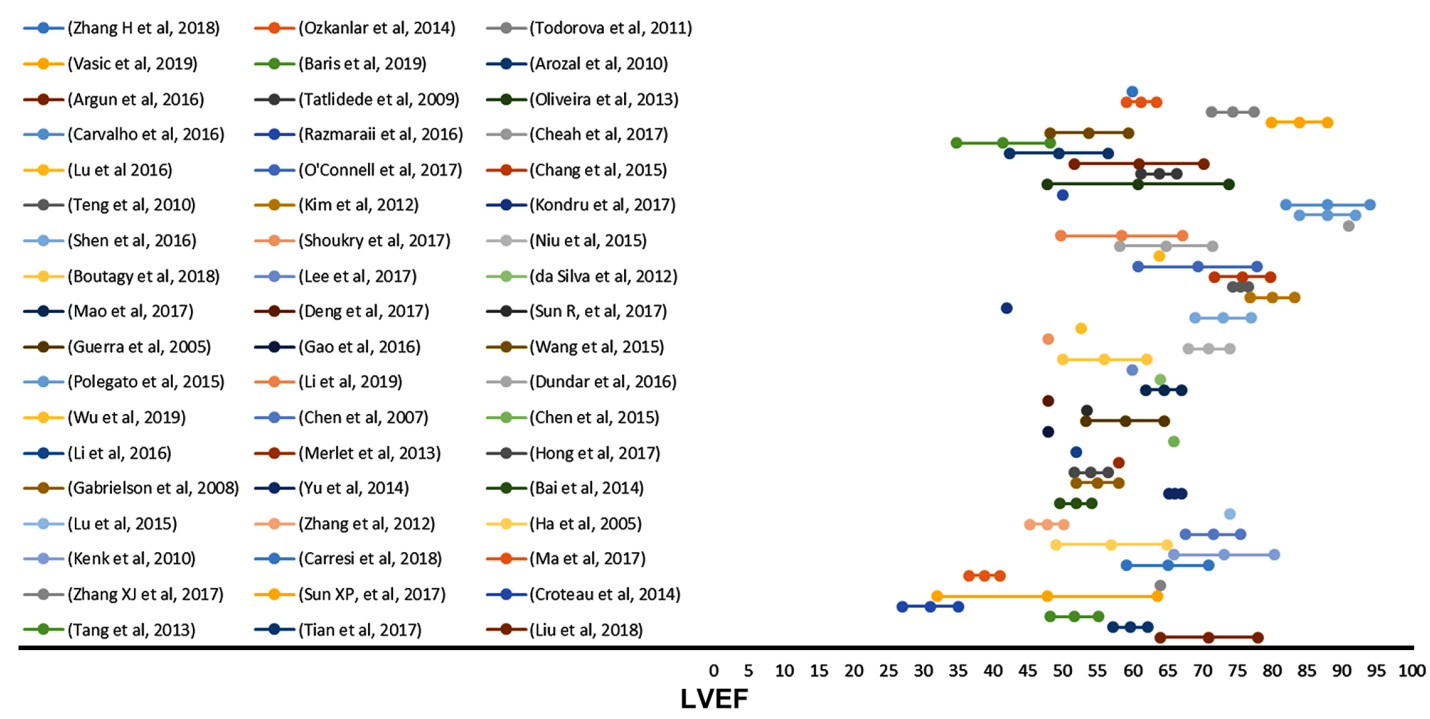

Figure 4. Suppressed LVEF values in rats due to anthracycline toxicity as reported in 54 relevant studies reviewed in the present report. LVEF, left ventricular ejection fraction.

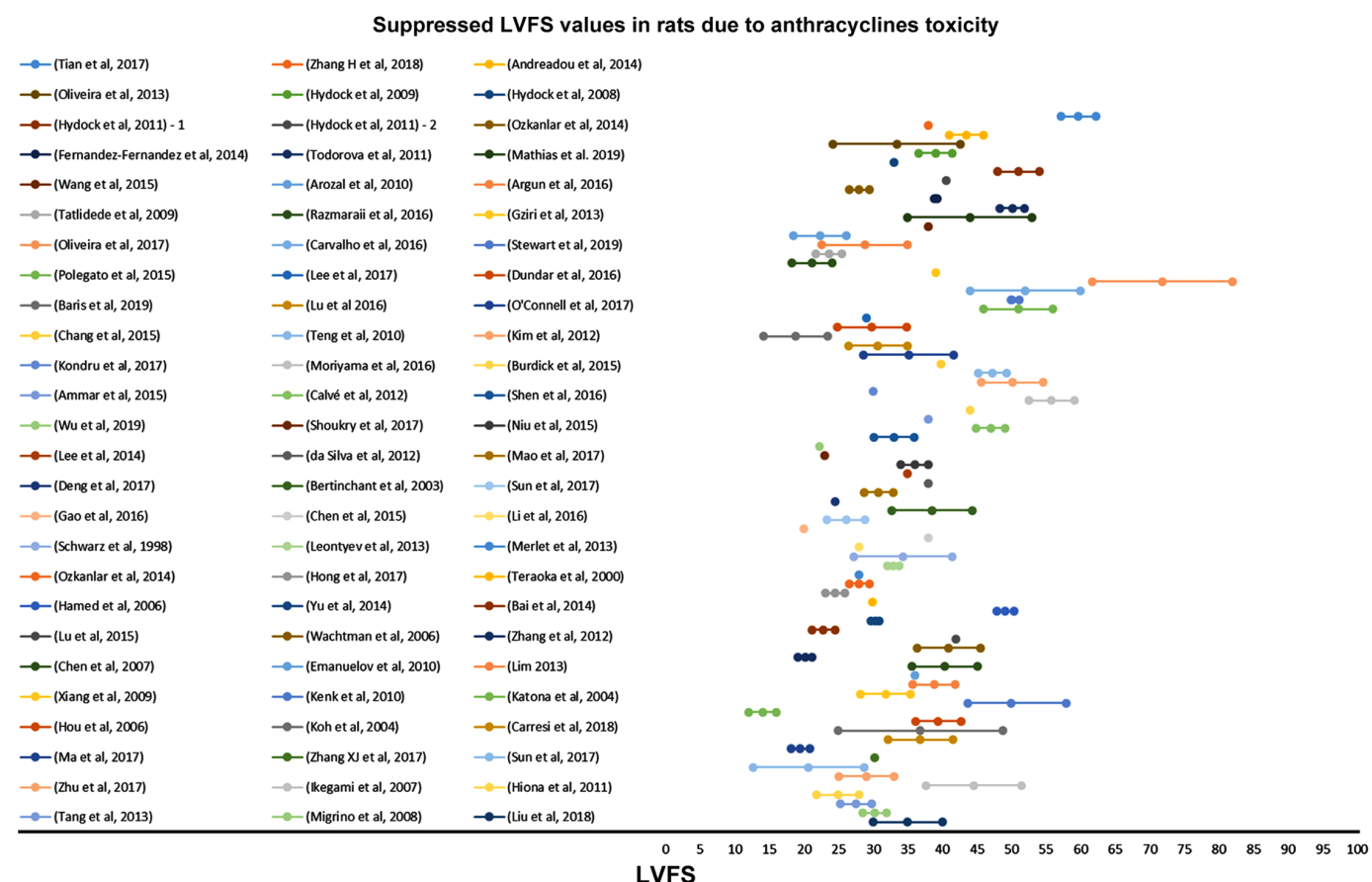

Figure 5. Suppressed LVFS values in rats due to anthracycline toxicity as reported in 78 relevant studies reviewed in the present report. LVFS, left ventricular fractional shortening.

In the current study a wide range of EF and FS decline due to anthracycline administration was observed. However, the trends of the said decline are easily identified, especially for FS values, thus rendering the establishment of minimum cut off values of decline feasible. The question remains, as it has also been identified for humans, whether the absolute suppressed values of EF and FS, combined or separately, or the $\%$ suppression caused by anthracyclines should be used to describe cardiotoxicity, and which of the two approaches could be more effective in prevention. In our study, it seems that setting a range for \% suppression of EF and FS could be more efficient in identifying early cardiotoxicity by counteracting the intra-individual variation of the absolute values.

In the current in depth review analysis, we did not identify differences between rat strains in terms of suppressed EF and FS values due to anthracycline administration. This is an interesting finding as it seems that the usual strains used in rat studies are equally prone to the cardiotoxic anthracycline potential. In animal models of genetically programmed hypertension and heart failure, it is found that doxorubicin administration did not lead to lower myocardial contractility compared to non-genetically modified strains (102). In addi- 
<smiles>COc1cccc2c1C(=O)c1c(O)c3c(c(O)c1C2=O)C[C@@](O)(C(=O)CO)C[C@H](OC1C[C@H](N)C(O)C(C)O1)C3</smiles>

Doxorubicin<smiles>COc1cccc2c1C(=O)c1c(O)c3c(c(O)c1C2=O)C[C@@](O)(C(C)=O)C[C@@H]3O[C@@H]1C[C@H](N)[C@@H](O)[C@H](C)O1</smiles>

Daunorubicin<smiles>COc1cccc2c1C(=O)c1c(O)c3c(c(O)c1C2=O)C[C@@](O)(C(=O)CO)C[C@H]3OC1C[C@H](N)[C@H](O)[C@H](C)O1</smiles>

Figure 6. Chemical structures of the three anthracyclines used to induce cardiotoxicity in the studies reviewed in the present report.

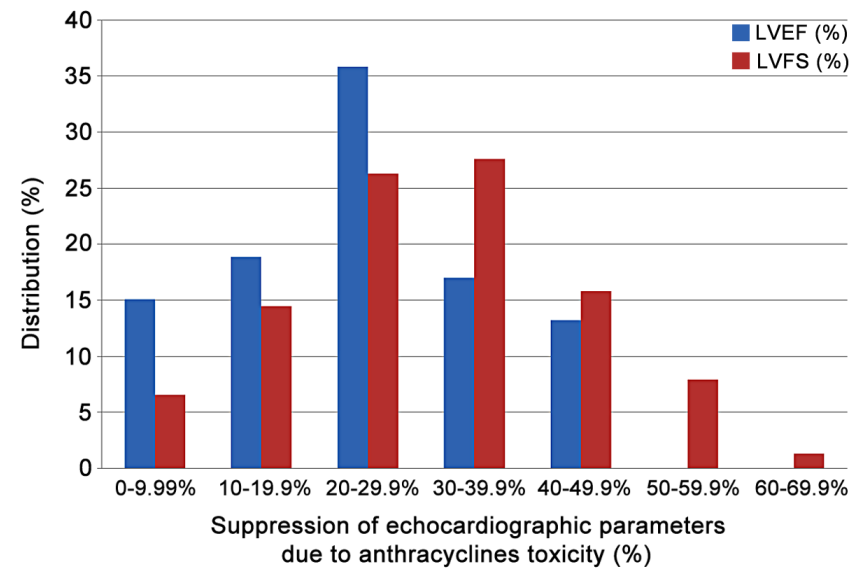

Figure 7. Percentiles distribution of \% suppression of LVEF and LVFS due to anthracycline toxicity as mentioned in the studies reviewed in the present report. LVEF, left ventricular ejection fraction; LVFS, left ventricular fractional shortening.

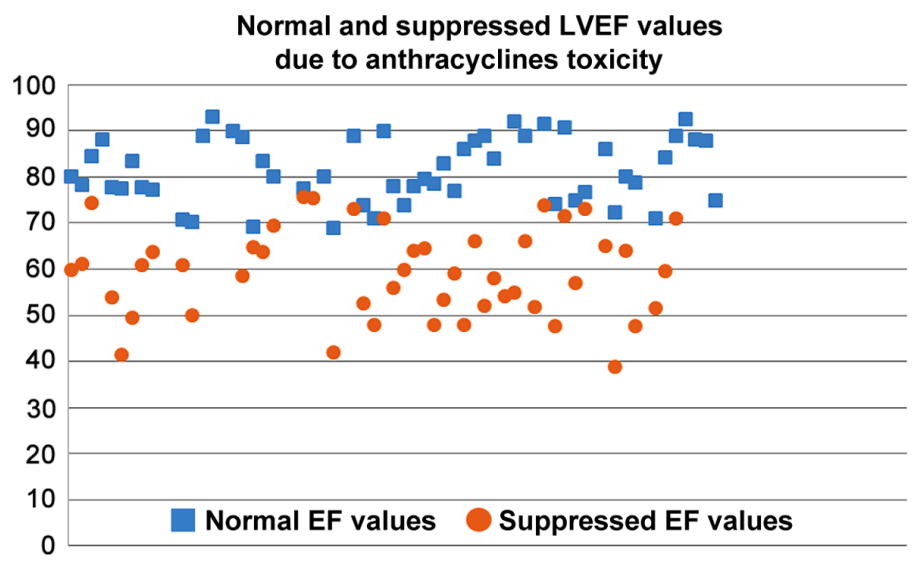

Figure 8. Scatter plot of normal (baseline) and suppressed LVEF values in rats due to anthracycline toxicity as reported the studies reviewed in the present report. LVEF, left ventricular ejection fraction.

tion, in the current systematic review, acute and chronic anthracyclines cardiotoxicity models were found equally potent in inducing cardiotoxicity based on evaluated echocardiographic indices.
Currently, when assessing chemicals toxicity, cardiac effects if monitored and detected in animal studies, mainly on the tissue level, are considered by the authorities, but cardiotoxicity, as such, is not described as a separate hazard class of 


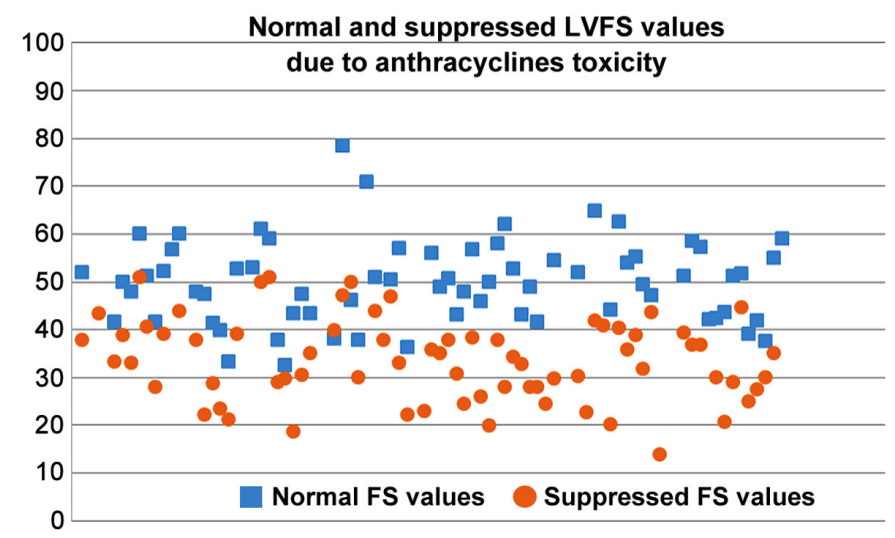

Figure 9. Scatter plot of normal (baseline) and suppressed LVFS values in rats due to anthracycline toxicity as reported in the studies reviewed in the present report. LVFS, left ventricular fractional shortening.

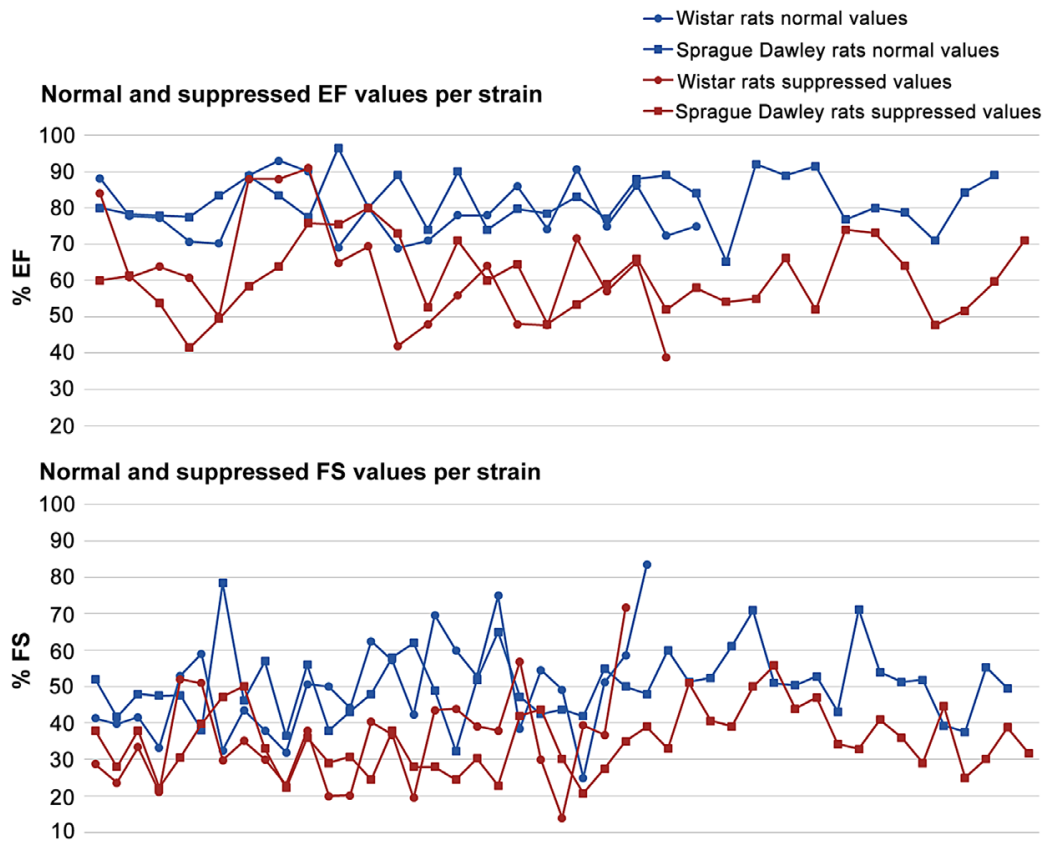

Figure 10. Normal and suppressed LVEF and LVFS values for the two main rat strains used in the studies reviewed in the present report. LVEF, left ventricular ejection fraction; LVFS, left ventricular fractional shortening.

chemical substances through the available regulations, both at a European level and world-wide. Therefore, chemicals other than pharmaceutical agents are recognised to be cardiotoxic after having exerted such deleterious effects on humans, based on epidemiological studies. In a previous review of our research team, the cardiac pathology and function impairment due to exposure to pesticides revealed that several cardiovascular complications have been reported in animal models including electrocardiogram abnormalities, myocardial infarction, impaired systolic and diastolic performance and histopathological findings, such as haemorrhage, vacuolization, signs of apoptosis and degeneration (103). In addition, there is evidence that short and/or long-term exposure to anabolic androgenic steroids is linked to a variety of cardiovascular complications which could be identified by using echocardiography or biochemical markers $(10,104,105)$. The published data suggest clearly that there is a need to establish regulatory criteria for assessing cardiotoxicity as an inherent property of a chemical substance well in advance, and characterize the risk of exposure to such chemicals through a well-developed regulatory network based on animal models, as is the case for other human health hazard classes, such as carcinogenicity. Regulatory established criteria will enable international organizations to early identify cardiotoxic effects and classify chemicals in order to avoid long-term cardiovascular complications. Specific classification criteria should be developed based on anatomical, histopathological, echocardiographic and biochemical criteria in animals developed in a way that could exclude confounding factors in the development of the observed cardiotoxicity. The results of the present study are promising in identifying echocardiographic criteria in rats for the establishment of cardiotoxicity. Further studies and meta-analyses are needed in order to evaluate other species, commonly used in research, and explore the possibility of early recognizing the onset of cardiotoxicity, possibly through monitoring of biochemical markers based on understanding of the mode of action. 


\section{Acknowledgements}

Not applicable

\section{Funding}

No funding was received.

\section{Availability of data and materials}

Not applicable

\section{Authors' contributions}

All authors have read and approved the final version of this manuscript. This report is part of the PhD Thesis of NG supervised by DS, KTo and DK and performed in the University of Thessaly. NG: organization and performing of the research, collecting data, writing of the research article. KT, CT: conceptualization of the project, setting criteria for the research, verification of the results, reviewing the manuscript, the statistics and the reference list, overall project management. RR, HN, GENK, JLCMD: data extraction, evaluation of the results, statistical analysis. DAS, DS, KTo, DK, CT: overall project overview, data assessment, evaluation of the results, evaluation of the applicability of the findings, reviewing and writing of the research article and plan assessment.

\section{Ethics approval and consent to participate}

\section{Not applicable}

\section{Patients consent for publication}

Not applicable

\section{Competing interests}

DAS is the Editor-in-Chief for the journal, but had no personal involvement in the reviewing process, or any influence in terms of adjudicating on the final decision, for this article. The positions and opinions presented in this article are those of the authors (NG, GENK, JLCMD) alone and are not intended to represent the views or any official position or scientific works of the European Agencies EFSA and ECHA. The other authors declare that they have no competing interests.

\section{References}

1. Zamorano JL, Lancellotti P, Rodriguez Muñoz D, Aboyans V, Asteggiano R, Galderisi M, Habib G, Lenihan DJ, Lip GYH, Lyon AR, et al; ESC Scientific Document Group: 2016 ESC Position Paper on cancer treatments and cardiovascular toxicity developed under the auspices of the ESC Committee for Practice Guidelines: The Task Force for cancer treatments and cardiovascular toxicity of the European Society of Cardiology (ESC). Eur Heart J 37: 2768-2801, 2016.

2. Plana JC, Galderisi M, Barac A, Ewer MS, Ky B, Scherrer-Crosbie M, Ganame J, Sebag IA, Agler DA, Badano LP, et al: Expert consensus for multimodality imaging evaluation of adult patients during and after cancer therapy: A report from the American Society of Echocardiography and the European Association of Cardiovascular Imaging. J Am Soc Echocardiogr 27: 911-939, 2014
3. Pardo Sanz A and Zamorano JL: 'Cardiotoxicity': time to define new targets? Eur Heart J 41: 1730-1732, 2020.

4. Park CJ, Branch ME, Vasu S and Melendez GC: The role of cardiac MRI in animal models of cardiotoxicity: hopes and challenges. J Cardiovasc Transl Res: Apr 4, 2020 (Epub ahead of print).

5. Sobczuk P, Czerwinska M, Kleibert M and CudnochJedrzejewska A: Anthracycline-induced cardiotoxicity and renin-angiotensin-aldosterone system-from molecular mechanisms to therapeutic applications. Heart Fail Rev: May 30, 2020 (Epub ahead of print).

6. Hashemzaei M, Karami SP, Delaramifar A, Sheidary A, Tabrizian K, Rezaee R, Shahsavand S, Arsene AL, Tsatsakis AM and Mohammad S: Anticancer effects of co-administration of daunorubicin and resveratrol in MOLT-4, U266 B1 and RAJI cell lines. Farmacia 64: 36-42, 2016.

7. Iranshahi M, Barthomeuf C, Bayet-Robert M, Chollet P, Davoodi D, Piacente S, Rezaee R and Sahebkar A: Drimane-type sesquiterpene coumarins from ferula gummosa fruits enhance doxorubicin uptake in doxorubicin-resistant human breast cancer cell line. J Tradit Complement Med 4: 118-125, 2014.

8. Schwarz ER, Pollick C, Dow J, Patterson M, Birnbaum Y and Kloner RA: A small animal model of non-ischemic cardiomyopathy and its evaluation by transthoracic echocardiography. Cardiovasc Res 39: 216-223, 1998.

9. Robert J: Preclinical assessment of anthracycline cardiotoxicity in laboratory animals: Predictiveness and pitfalls. Cell Biol Toxicol 23: 27-37, 2007.

10. Germanakis I, Tsarouhas K, Fragkiadaki P, Tsitsimpikou C, Goutzourelas N, Champsas MC, Stagos D, Rentoukas E and Tsatsakis AM: Oxidative stress and myocardial dysfunction in young rabbits after short term anabolic steroids administration. Food Chem Toxicol 61: 101-105, 2013.

11. Moher D, Shamseer L, Clarke M, Ghersi D, Liberati A, Petticrew M, Shekelle P and Stewart LA; PRISMA-P Group: Preferred reporting items for systematic review and meta-analysis protocols (PRISMA-P) 2015 statement. Syst Rev 4: 1, 2015.

12. Zacchigna S, Paldino A, Falcao-Pires I, Daskalopoulos EP, Dal Ferro M, Vodret S, Lesizza P, Cannatà A, Daniela Miranda-Silva D, et al: Toward standardization of echocardiography for the evaluation of left ventricular function in adult rodents: a position paper of the ESC Working Group on Myocardial Function. Cardiovasc Res: May 4, 2020 (Epub ahead of print).

13. Liu J and Rigel DF: Echocardiographic examination in rats and mice. Methods Mol Biol 573: 139-155, 2009.

14. Zhang H, Lu X, Liu Z and Du K: Rosuvastatin reduces the pro-inflammatory effects of adriamycin on the expression of HMGB1 and RAGE in rats. Int J Mol Med 42: 3415-3423, 2018.

15. Tian XQ, Ni XW, Xu HL, Zheng L, ZhuGe DL, Chen B, Lu CT, Yuan JJ and Zhao YZ: Prevention of doxorubicin-induced cardiomyopathy using targeted MaFGF mediated by nanoparticles combined with ultrasound-targeted MB destruction. Int J Nanomedicine 12: 7103-7119, 2017.

16. Andreadou I, Mikros E, Ioannidis K, Sigala F, Naka K, Kostidis S, Farmakis D, Tenta R, Kavantzas N, Bibli SI, et al: Oleuropein prevents doxorubicin-induced cardiomyopathy interfering with signaling molecules and cardiomyocyte metabolism. J Mol Cell Cardiol 69: 4-16, 2014.

17. Oliveira MS, Melo MB, Carvalho JL, Melo IM, Lavor MSI, Gomes DA, de Goes AM and Melo MM: Doxorubicin cardiotoxicity and cardiac function improvement after stem cell therapy diagnosed by strain echocardiography. J Cancer Sci Ther 5: 52-57, 2013.

18. Hydock DS, Lien CY and Hayward R: Anandamide preserves cardiac function and geometry in an acute doxorubicin cardiotoxicity rat model. J Cardiovasc Pharmacol Ther 14: 59-67, 2009.

19. Fernandez-Fernandez A, Carvajal DA, Lei T and McGoron AJ: Chemotherapy-induced changes in cardiac capillary permeability measured by fluorescent multiple indicator dilution. Ann Biomed Eng 42: 2405-2415, 2014.

20. Todorova VK, Kaufmann Y and Klimberg VS: Increased efficacy and reduced cardiotoxicity of metronomic treatment with cyclophosphamide in rat breast cancer. Anticancer Res 31: 215-220, 2011.

21. Vasić M, Lončar-Turukalo T, Tasić T, Matić M, Glumac S, Bajić D, Popović B and Japundžić-Žigon N: Cardiovascular variability and $\beta$-ARs gene expression at two stages of doxorubicin-induced cardiomyopathy. Toxicol Appl Pharmacol 362: 43-51, 2019. 
22. Mathias LMBS, Alegre PHC, Dos Santos IOF, Bachiega T, Figueiredo AM, Chiuso-Minicucci F, Fernandes AA, Bazan SGZ, Minicucci MF, Azevedo PS, et al: Euterpe oleracea Mart. (Açai) supplementation attenuates acute doxorubicin-induced cardiotoxicity in rats. Cell Physiol Biochem 53: 388-399, 2019.

23. Wang X, Chen L, Wang T, Jiang X, Zhang H, Li P, Lv B and Gao X: Ginsenoside Rg3 antagonizes adriamycin-induced cardiotoxicity by improving endothelial dysfunction from oxidative stress via upregulating the Nrf2-ARE pathway through the activation of akt. Phytomedicine 22: 875-884, 2015.

24. Arozal W, Watanabe K, Veeraveedu PT, Thandavarayan RA, Harima M, Sukumaran V, Suzuki K, Kodama M and Aizawa Y: Effect of telmisartan in limiting the cardiotoxic effect of daunorubicin in rats. J Pharm Pharmacol 62: 1776-1783, 2010.

25. Argun M, Üzüm K, Sönmez MF, Özyurt A, Derya K, Çilenk KT, Unalmış S, Pamukcu Ö, Baykan A, Narin F, et al: Cardioprotective effect of metformin against doxorubicin cardiotoxicity in rats. Anatol J Cardiol 16: 234-241, 2016.

26. Tatlidede E, Sehirli O, Velioğlu-Oğünc A, Cetinel S, Yeğen BC, Yarat A, Süleymanoğlu S and Sener G: Resveratrol treatment protects against doxorubicin-induced cardiotoxicity by alleviating oxidative damage. Free Radic Res 43: 195-205, 2009.

27. Razmaraii N, Babaei H, Mohajjel Nayebi A, Assadnassab G, Ashrafi Helan J and Azarmi Y: Crocin treatment prevents doxorubicin-induced cardiotoxicity in rats. Life Sci 157: 145-151, 2016.

28. Gziri MM, Pokreisz P, De Vos R, Verbeken E, Debiève F, Mertens L, Janssens SP and Amant F: Fetal rat hearts do not display acute cardiotoxicity in response to maternal Doxorubicin treatment. J Pharmacol Exp Ther 346: 362-369, 2013.

29. Oliveira LF, O'Connell JL, Carvalho EE, Pulici ECC, Romano MMD, Maciel BC and Simões MV: Comparison between radionuclide ventriculography and echocardiography for quantification of left ventricular systolic function in rats exposed to doxorubicin. Arq Bras Cardiol 108: 12-20, 2017

30. Carvalho PB, Gonçalves AF, Alegre PH, Azevedo PS, Roscani MG, Bergamasco CM, Modesto PN, Fernandes AA, Minicucci MF, Paiva SA, et al: Pamidronate attenuates oxidative stress and energetic metabolism changes but worsens functional outcomes in acute doxorubicin-induced cardiotoxicity in rats. Cell Physiol Biochem 40: 431-442, 2016.

31. Stewart LK, Smoak P, Hydock DS, Hayward R, O'Brien K, Lisano JK, Boeneke C, Christensen M and Mathias A: Milk and kefir maintain aspects of health during doxorubicin treatment in rats. J Dairy Sci 102: 1910-1917, 2019.

32. Polegato BF, Minicucci MF, Azevedo PS, Carvalho RF, Chiuso-Minicucci F, Pereira EJ, Paiva SA, Zornoff LA Okoshi MP, Matsubara BB, et al: Acute doxorubicin-induced cardiotoxicity is associated with matrix metalloproteinase-2 alterations in rats. Cell Physiol Biochem 35: 1924-1933, 2015.

33. Lee KH, Cho H, Lee S, Woo JS, Cho BH, Kang JH, Jeong YM, Cheng XW and Kim W: Enhanced-autophagy by exenatide mitigates doxorubicin-induced cardiotoxicity. Int J Cardiol 232: 40-47, 2017.

34. Cheah HY, Šarenac O, Arroyo JJ, Vasić M, Lozić M, Glumac S, Hoe SZ, Hindmarch CCT, Murphy D, Kiew LV, et al: Hemodynamic effects of HPMA copolymer based doxorubicin conjugate: A randomized controlled and comparative spectral study in conscious rats. Nanotoxicology 11: 210-222, 2017.

35. Li X, Xu G, Wei S, Zhang B, Yao H, Chen Y, Liu W, Wang B, Zhao $\mathrm{J}$ and Gao Y: Lingguizhugan decoction attenuates doxorubicin-induced heart failure in rats by improving TT-SR microstructural remodeling. BMC Complement Altern Med 19: $360,2019$.

36. Dundar HA, Kiray M, Kir M, Kolatan E, Bagriyanik A, Altun Z, Aktas S, Ellidokuz H, Yilmaz O, Mutafoglu K, et al: Protective effect of acetyl-L-carnitine against doxorubicin-induced cardiotoxicity in wistar albino rats. Arch Med Res 47: 506-514, 2016.

37. Barış VO, Gedikli E, Yersal N, Müftüoğlu S and Erdem A: Protective effect of taurine against doxorubicin-induced cardiotoxicity in rats: Echocardiographical and histological findings. Amino Acids 51: 1649-1655, 2019.

38. Lu PP, Ma J, Liang XP, Guo CX, Yang YK, Yang KQ, Shen QM, Ma LH and Zhou XL: Xinfuli improves cardiac function, histopathological changes and attenuate cardiomyocyte apoptosis in rats with doxorubicin-induced cardiotoxicity. J Geriatr Cardiol 13: 968-972, 2016.
39. O'Connell JL, Romano MM, Campos Pulici EC, Carvalho EEV, de Souza FR, Tanaka DM, Maciel BC, Salgado HC, Fazan-Júnior R, Rossi MA, et al: Short-term and long-term models of doxorubicin-induced cardiomyopathy in rats: A comparison of functional and histopathological changes. Exp Toxicol Pathol 69: 213-219, 2017.

40. Chang SA, Lim BK, Lee YJ, Hong MK, Choi JO and Jeon ES: A novel angiotensin type I receptor antagonist, Fimasartan, prevents Doxorubicin-induced cardiotoxicity in rats. J Korean Med Sci 30: 559-568, 2015

41. Teng LL, Shao L, Zhao YT, Yu X, Zhang DF and Zhang H: The beneficial effect of $n-3$ polyunsaturated fatty acids on doxorubicin-induced chronic heart failure in rats. J Int Med Res 38: 940-948, 2010

42. Kim YH, Kim M, Park SM, Kim SH, Lim SY, Ahn JC, Song WH and Shim WJ: Discordant impairment of multidirectional myocardial deformation in rats with Doxorubicin induced cardiomyopathy. Echocardiography 29: 720-728, 2012.

43. Kondru SK, Potnuri AG, Allakonda L and Konduri P: Histamine 2 receptor antagonism elicits protection against doxorubicin-induced cardiotoxicity in rodent model. Mol Cell Biochem 441: 77-88, 2018.

44. Moriyama T, Kemi M and Horie T: Elevated cardiac 3-deoxyglucosone, a highly reactive intermediate in glycation reaction, in doxorubicin-induced cardiotoxicity in rats. Pathophysiology 23: 237-242, 2016.

45. Burdick J, Berridge B and Coatney R: Strain echocardiography combined with pharmacological stress test for early detection of anthracycline induced cardiomyopathy. J Pharmacol Toxicol Methods 73: 15-20, 2015.

46. Ammar HI, Sequiera GL, Nashed MB, Ammar RI, Gabr HM, Elsayed HE, Sareen N, Rub EA, Zickri MB and Dhingra S: Comparison of adipose tissue- and bone marrow-derived mesenchymal stem cells for alleviating doxorubicin-induced cardiac dysfunction in diabetic rats. Stem Cell Res Ther 6: 148, 2015

47. Calvé A, Haddad R, Barama SN, Meilleur M, Sebag IA and Chalifour LE: Cardiac response to doxorubicin and dexrazoxane in intact and ovariectomized young female rats at rest and after swim training. Am J Physiol Heart Circ Physiol 302: H2048-H2057, 2012

48. Shen LJ, Lu S, Zhou YH, Li L, Xing QM and Xu YL: Developing a rat model of dilated cardiomyopathy with improved survival. J Zhejiang Univ Sci B 17: 975-983, 2016.

49. Wu Z, Zhao X, Miyamoto A, Zhao S, Liu C, Zheng W and Wang H: Effects of steroidal saponins extract from Ophiopogon japonicus root ameliorates doxorubicin-induced chronic heart failure by inhibiting oxidative stress and inflammatory response. Pharm Biol 57: 176-183, 2019.

50. Shoukry HS, Ammar HI, Rashed LA, Zikri MB, Shamaa AA, Abou Elfadl SG, Rub EA, Saravanan S and Dhingra S: Prophylactic supplementation of resveratrol is more effective than its therapeutic use against doxorubicin induced cardiotoxicity. PLoS One 12: e0181535, 2017.

51. Niu QY, Li ZY, Du GH and Qin XM: (1)H NMR based metabolomic profiling revealed doxorubicin-induced systematic alterations in a rat model. J Pharm Biomed Anal 118: 338-348, 2016.

52. Boutagy NE, Wu J, Cai Z, Zhang W, Booth CJ, Kyriakides TC, Pfau D, Mulnix T, Liu Z, Miller EJ, et al: In vivo reactive oxygen species detection with a novel positron emission tomography tracer, 18F-DHMT, allows for early detection of anthracycline-induced cardiotoxicity in rodents. JACC Basic Transl Sci 3: 378-390, 2018

53. Lee PJ, Rudenko D, Kuliszewski MA, Liao C, Kabir MG, Connelly KA and Leong-Poi H: Survivin gene therapy attenuates left ventricular systolic dysfunction in doxorubicin cardiomyopathy by reducing apoptosis and fibrosis. Cardiovasc Res 101: 423-433, 2014

54. da Silva MG, Mattos E, Camacho-Pereira J, Domitrovic T, Galina A, Costa MW and Kurtenbach E: Cardiac systolic dysfunction in doxorubicin-challenged rats is associated with upregulation of MuRF2 and MuRF3 E3 ligases. Exp Clin Cardiol 17: 101-109, 2012

55. Mao C, Hou X, Wang B, Chi J, Jiang Y, Zhang C and Li Z: Intramuscular injection of human umbilical cord-derived mesenchymal stem cells improves cardiac function in dilated cardiomyopathy rats. Stem Cell Res Ther 8: 18, 2017.

56. Deng B, Wang JX, Hu XX, Duan P, Wang L, Li Y and Zhu QL: Nkx2.5 enhances the efficacy of mesenchymal stem cells transplantation in treatment heart failure in rats. Life Sci 182: 65-72, 2017. 
57. Bertinchant JP, Polge A, Juan JM, Oliva-Lauraire MC, Giuliani I, Marty-Double C, Burdy JY, Fabbro-Peray P, Laprade M, Bali JP, et al: Evaluation of cardiac troponin I and T levels as markers of myocardial damage in doxorubicin-induced cardiomyopathy rats, and their relationship with echocardiographic and histological findings. Clin Chim Acta 329: 39-51, 2003.

58. Sun R, Wang J, Zheng Y, Li X, Xie T, Li R, Liu M, Cao Y, Lu L, Zhang Q, et al: Traditional Chinese medicine baoxin decoction improves cardiac fibrosis of rats with dilated cardiomyopathy. Exp Ther Med 13: 1900-1906, 2017.

59. Guerra J, De Jesus A, Santiago-Borrero P, Roman-Franco A, Rodríguez E and Crespo MJ: Plasma nitric oxide levels used as an indicator of doxorubicin-induced cardiotoxicity in rats. Hematol J 5: 584-588, 2005.

60. Gao Y, Yang H, Fan Y, Li L, Fang J and Yang W: Hydrogen-rich saline attenuates cardiac and hepatic injury in doxorubicin rat model by inhibiting inflammation and apoptosis. Mediators Inflamm 2016: 1320365, 2016

61. Chen Y, Tang Y, Xiang Y, Xie YQ, Huang XH and Zhang YC: Shengmai injection improved doxorubicin-induced cardiomyopathy by alleviating myocardial endoplasmic reticulum stress and caspase-12 dependent apoptosis. BioMed Res Int 2015: 952671,2015

62. Li H, Mao Y, Zhang Q, Han Q, Man Z, Zhang J, Wang X, $\mathrm{Hu} \mathrm{R}$, Zhang $\mathrm{X}$, Irwin DM, et al: Xinmailong mitigated epirubicin-induced cardiotoxicity via inhibiting autophagy. J Ethnopharmacol 192: 459-470, 2016.

63. Leontyev S, Schlegel F, Spath C, Schmiedel R, Nichtitz M, Boldt A, Rübsamen R, Salameh A, Kostelka M, Mohr FW, et al: Transplantation of engineered heart tissue as a biological cardiac assist device for treatment of dilated cardiomyopathy. Eur J Heart Fail 15: 23-35, 2013

64. Merlet N, Piriou N, Rozec B, Grabherr A, Lauzier B, Trochu JN and Gauthier C: Increased beta2-adrenoceptors in doxorubicin-induced cardiomyopathy in rat. PLoS One 8: e64711, 2013.

65. Ozkanlar Y, Aktas MS, Turkeli M, Erturk N, Oruc E, Ozkanlar S Kirbas A, Erdemci B and Aksakal E: Effects of ramipril and darbepoetin on electromechanical activity of the heart in doxorubicin-induced cardiotoxicity. Int J Cardiol 173: 519-521, 2014.

66. Hong YM, Lee H, Cho MS and Kim KC: Apoptosis and remodeling in adriamycin-induced cardiomyopathy rat model Korean J Pediatr 60: 365-372, 2017

67. Teraoka K, Hirano M, Yamaguchi K and Yamashina A Progressive cardiac dysfunction in adriamycin-induced cardiomyopathy rats. Eur J Heart Fail 2: 373-378, 2000.

68. Hamed S, Barshack I, Luboshits G, Wexler D, Deutsch V, Keren $\mathrm{G}$ and George J: Erythropoietin improves myocardial performance in doxorubicin-induced cardiomyopathy. Eur Heart J 27: 1876-1883, 2006.

69. Gabrielson KL, Mok GS, Nimmagadda S, Bedja D, Pin S, Tsao A, Wang Y, Sooryakumar D, Yu SJ, Pomper MG, et al: Detection of dose response in chronic doxorubicin-mediated cell death with cardiac technetium $99 \mathrm{~m}$ annexin V single-photon emission computed tomography. Mol Imaging 7: 132-138, 2008

70. Yu Q, Li Q, Na R, Li X, Liu B, Meng L, Liutong H, Fang W, Zhu $\mathrm{N}$ and Zheng $\mathrm{X}$ : Impact of repeated intravenous bone marrow mesenchymal stem cells infusion on myocardial collagen network remodeling in a rat model of doxorubicin-induced dilated cardiomyopathy. Mol Cell Biochem 387: 279-285, 2014.

71. Bai J, Gu R, Wang B, Zhang N, Kang L and Xu B: Overexpression of integrin-linked kinase improves cardiac function in a rat model of doxorubicin-induced chronic heart failure. Zhonghua Xin Xue Guan Bing Za Zhi 42: 225-229, 2014 (In Chinese).

72. Lu XL, Tong YF, Liu Y, Xu YL, Yang H, Zhang GY, Li XH and Zhang HG: Gaq protein carboxyl terminus imitation polypeptide GCIP-27 improves cardiac function in chronic heart failure rats PLoS One 10: e0121007, 2015.

73. Wachtman LM, Browning MD, Bedja D, Pin S and Gabrielson KL: Validation of the use of long-term indwelling jugular catheters in a rat model of cardiotoxicity. J Am Assoc Lab Anim Sci 45: 55-64, 2006

74. Zhang J, Zhang L, Wu Q, Liu H and Huang L: Recombinant human brain natriuretic peptide therapy combined with bone mesenchymal stem cell transplantation for treating heart failure in rats. Mol Med Rep 7: 628-632, 2013.

75. Chen X, Chen Y, Bi Y, Fu N, Shan C, Wang S, Aslam S, Wang PW and $\mathrm{Xu}$ J: Preventive cardioprotection of erythropoietin against doxorubicin-induced cardiomyopathy. Cardiovasc Drugs Ther 21: 367-374, 2007
76. Ha JW, Kang SM, Pyun WB, Lee JY, Ahn MY, Kang WC, Jeon TJ, Chung N, Lee JD and Cho SH: Serial assessment of myocardial properties using cyclic variation of integrated backscatter in an adriamycin-induced cardiomyopathy rat model. Yonsei Med J 46: 73-77, 2005.

77. Emanuelov AK, Shainberg A, Chepurko Y, Kaplan D, Sagie A, Porat E, Arad M and Hochhauser E: Adenosine A3 receptor-mediated cardioprotection against doxorubicin-induced mitochondrial damage. Biochem Pharmacol 79: 180-187, 2010.

78. Lim SC: Interrelation between expression of ADAM 10 and MMP 9 and synthesis of peroxynitrite in doxorubicin induced cardiomyopathy. Biomol Ther (Seoul) 21: 371-380, 2013.

79. Hydock DS, Lien CY, Schneider CM and Hayward R: Exercise preconditioning protects against doxorubicin-induced cardiac dysfunction. Med Sci Sports Exerc 40: 808-817, 2008.

80. Xiang P, Deng HY, Li K, Huang G-Y, Chen Y, Tu L, Ng PC, Pong NH, Zhao H, Zhang L, et al: Dexrazoxane protects against doxorubicin-induced cardiomyopathy: Upregulation of $\mathrm{Akt}$ and Erk phosphorylation in a rat model. Cancer Chemother Pharmacol 63: 343-349, 2009.

81. Kenk M, Thackeray JT, Thorn SL, Dhami K, Chow BJ, Ascah KJ, DaSilva JN and Beanlands RS: Alterations of pre- and postsynaptic noradrenergic signaling in a rat model of adriamycin-induced cardiotoxicity. J Nucl Cardiol 17: 254-263, 2010.

82. Katona M, Boros K, Sántha P, Ferdinandy P, Dux M and Jancsó G: Selective sensory denervation by capsaicin aggravates adriamycin-induced cardiomyopathy in rats. Naunyn Schmiedebergs Arch Pharmacol 370: 436-443, 2004.

83. Hydock DS, Parry TL, Jensen BT, Lien CY, Schneider CM and Hayward R: Effects of endurance training on combined goserelin acetate and doxorubicin treatment-induced cardiac dysfunction. Cancer Chemother Pharmacol 68: 685-692, 2011.

84. Hou XW, Son J, Wang Y, Ru YX, Lian Q, Majiti W, Amazouzi A, Zhou YL, Wang PX and Han ZC: Granulocyte colony-stimulating factor reduces cardiomyocyte apoptosis and improves cardiac function in adriamycin-induced cardiomyopathy in rats. Cardiovasc Drugs Ther 20: 85-91, 2006.

85. Hydock DS, Lien CY, Jensen BT, Schneider CM and Hayward R: Exercise preconditioning provides long-term protection against early chronic doxorubicin cardiotoxicity. Integr Cancer Ther 10: 47-57, 2011.

86. Koh E, Nakamura $\mathrm{T}$ and Takahashi $\mathrm{H}$ : Troponin-T and brain natriuretic peptide as predictors for adriamycin-induced cardiomyopathy in rats. Circ J 68: 163-167, 2004.

87. Carresi C, Musolino V, Gliozzi M, Maiuolo J, Mollace R, Nucera S, Maretta A, Sergi D, Muscoli S, Gratteri S, et al: Anti-oxidant effect of bergamot polyphenolic fraction counteracts doxorubicin-induced cardiomyopathy: Role of autophagy and c-kitposCD45negCD31neg cardiac stem cell activation. J Mol Cell Cardiol 119: 10-18, 2018.

88. Ma H, Kong J, Wang YL, Li JL, Hei NH, Cao XR, Yang JJ, Yan WJ, Liang WJ, Dai HY, et al: Angiotensin-converting enzyme 2 overexpression protects against doxorubicin-induced cardiomyopathy by multiple mechanisms in rats. Oncotarget 8 : 24548-24563, 2017.

89. Zhang XJ, Cao XQ, Zhang CS and Zhao Z: 17ß-estradiol protects against doxorubicin-induced cardiotoxicity in male Sprague-Dawley rats by regulating NADPH oxidase and apoptosis genes. Mol Med Rep 15: 2695-2702, 2017.

90. Sun XP, Wan LL, Yang QJ, Huo Y, Han YL and Guo C: Scutellarin protects against doxorubicin-induced acute cardiotoxicity and regulates its accumulation in the heart. Arch Pharm Res 40: 875-883, 2017.

91. Zhu HJ, Han ZY, He SF, Jin S-Y, Xu S-J, Fang X-D and Zhang Y: Specific MicroRNAs comparisons in hypoxia and morphine preconditioning against hypoxia-reoxgenation injury with and without heart failure. Life Sci 170: 82-92, 2017

92. Croteau E, Tremblay S, Gascon S, Dumulon-Perreault V,Labbé SM, Rousseau JA, Cunnane SC, Carpentier AC, Bénard F and Lecomte R: [(11)C]-Acetoacetate PET imaging: A potential early marker for cardiac heart failure. Nucl Med Biol 41: 863-870, 2014.

93. Ikegami E, Fukazawa R, Kanbe M, Watanabe M, Abe M, Watanabe M, Kamisago M, Hajikano M, Katsube Y and Ogawa S: Edaravone, a potent free radical scavenger, prevents anthracycline-induced myocardial cell death. Circ J 71: 1815-1820, 2007

94. Hiona A, Lee AS, Nagendran J, Xie X, Connolly AJ, Robbins RC and Wu JC: Pretreatment with angiotensin-converting enzyme inhibitor improves doxorubicin-induced cardiomyopathy via preservation of mitochondrial function. J Thorac Cardiovase Surg 142: 396-403.e3, 2011 
95. Tang DX, Zhao HP, Pan CS, Liu YY, Wei XH, Yang XY, Chen YY, Fan JY, et al: QiShenYiQi pills, a compound Chinese medicine, ameliorates doxorubicin-induced myocardial structure damage and cardiac dysfunction in rats. Evid Based Complement Alternat Med: eCAM 2013: 480597, 2013.

96. Migrino RQ, Aggarwal D, Konorev E, Brahmbhatt T, Bright M and Kalyanaraman B: Early detection of doxorubicin cardiomyopathy using two-dimensional strain echocardiography. Ultrasound Med Biol 34: 208-214, 2008.

97. Liu Y, Xu W, Xiong Y, Du G and Qin X: Evaluations of the effect of HuangQi against heart failure based on comprehensive echocardiography index and metabonomics. Phytomedicine 50: 205-212, 2018.

98.Liu X, Gu X, Li Z, Li X, Li H, Chang J, Chen P, Jin J, Xi B, Chen D, et al: Neuregulin-1/erbB-activation improves cardiac function and survival in models of ischemic, dilated, and viral cardiomyopathy. J Am Coll Cardiol 48: 1438-1447, 2006.

99. Cadeddu Dessalvi C, Pepe A, Penna C, Gimelli A, Madonna R, Mele D, Monte I, Novo G, Nugara C, Zito C, et al: Sex differences in anthracycline-induced cardiotoxicity: The benefits of estrogens. Heart Fail Rev 24: 915-925, 2019.

100. Swain SM, Whaley FS and Ewer MS: Congestive heart failure in patients treated with doxorubicin: A retrospective analysis of three trials. Cancer 97: 2869-2879, 2003.
101. Blanter JB and Frishman WH: The preventive role of angiotensin converting enzyme inhibitors/angiotensin-II receptor blockers and $\beta$-adrenergic blockers in anthracycline- and trastuzumab-induced cardiotoxicity. Cardiol Rev 27: 256-259, 2019.

102. Sharkey LC, Radin MJ, Heller L, Rogers LK, Tobias A, Matise I, Wang Q, Apple FS and McCune SA: Differential cardiotoxicity in response to chronic doxorubicin treatment in male spontaneous hypertension-heart failure (SHHF), spontaneously hypertensive (SHR), and Wistar Kyoto (WKY) rats. Toxicol Appl Pharmacol 273: 47-57, 2013.

103. Georgiadis N, Tsarouhas K, Tsitsimpikou C, Vardavas A, Rezaee R, Germanakis I, Tsatsakis A, Stagos D and Kouretas D: Pesticides and cardiotoxicity. Where do we stand? Toxicol Appl Pharmacol 353: 1-14, 2018.

104. Vasilaki F, Tsitsimpikou C, Tsarouhas K, Germanakis I, Tzardi M, Kavvalakis M, Ozcagli E, Kouretas D and Tsatsakis AM: Cardiotoxicity in rabbits after long-term nandrolone decanoate administration. Toxicol Lett 241: 143-151, 2016.

105. Achar S, Rostamian A and Narayan SM: Cardiac and metabolic effects of anabolic-androgenic steroid abuse on lipids, blood pressure, left ventricular dimensions, and rhythm. Am J Cardiol 106: 893-901, 2010.

c) (i) $(9$ This work is licensed under a Creative Commons

EY NO ND Attribution-NonCommercial-NoDerivatives 4.0 International (CC BY-NC-ND 4.0) License. 